\title{
Impactos socioambientais devidos à geração de energia elétrica de carvão mineral no Município de Figueira (Estado do Paraná, Sul do Brasil)
}

\author{
Vinicius G. M. Silva, Fidéllis B. G. L. Estanislau e Carlos \\ E. Velasquez*
}

Universidade Federal de Minas Gerais. Escola de Engenharia. Departamento de Engenharia Nuclear. Avenida Antônio Carlos, 6627. Pampulha. Belo Horizonte-MG, Brasil (CEP 31270-901).*E-mail: carlosvelcab@nuclear.ufmg.br.

Resumo. Entre as várias fontes de geração de energia elétrica no mundo, as termoelétricas a carvão são as que mais contribuem para a oferta de energia elétrica, entretanto emitem grandes quantidades de poluentes na atmosfera. 0 presente estudo busca quantificar os danos à saúde devido às emissões dos poluentes produzidas na Termoelétrica a carvão mineral no Município de Figueira, localizada no Estado do Paraná, que tem capacidade de geração elétrica de $20 \mathrm{MW}$. Este estudo é realizado em duas áreas, no município de Figueira $\left(25 \mathrm{~km}^{2}\right)$ e englobando outros municípios nas proximidades $\left(2.500 \mathrm{~km}^{2}\right)$. Para calcular os impactos socioambientais ocasionados pelo funcionamento da usina, utiliza-se o SIMPACTS, que estima e quantifica os custos de danos ambientais e à saúde pelas emissões dos gases $\mathrm{SO}_{\mathrm{x}}, \mathrm{NO}_{\mathrm{x}} \mathrm{e}$ de material particulado, além de mostrar sua dispersão em torno da usina. Os danos para o Município de Figueira custam em média US\$ 56,60/GWh, atingindo no ano de maior poluição um total de US\$ 127,60/GWh. Levando em consideração a região no entorno $\left(2.500 \mathrm{~km}^{2}\right)$, a média dos custos dos impactos pela poluição aumenta para US\$ 4.475,50/GWh, com um pico de US\$ 17.675,30/GWh, em 2017. Os resultados evidenciam uma disparidade dos impactos entre os anos de maior e menor emissão de poluentes, podendo indicar que um controle rigoroso das emissões pode causar uma redução significativa nos mesmos.

Palavras-chave: Energia; Termelétrica; Figueira; Poluição; Saúde; Carvão.

Abstract. Socio-environmental impacts due to the electric power generation at the Figueira Coal Power Plant (Paraná State, Southern Brazil). Among various sources of electricity generation in the world, coal-fired power plants are the ones that contribute the most to the electricity supply; however they emit large amounts of pollutants into the atmosphere. The present study intends to quantify the health effects due to pollutant emissions produced around the coal power plant at Municipality Figueira, located in Paraná State, Brazil, which have $20 \mathrm{MW}$ of
Recebido

07/08/2020

Aceito

10/04/2021

Disponível on line

12/04/2021

Publicado

$30 / 04 / 2021$

Acesso aberto

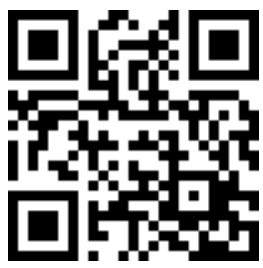

ORCID

(D) 0000-0002-4097-6580 Vinicius G. M. Silva

D 0000-0002-8617-9413

Fidéllis B. G. L.

Estanislau

D 0000-0002-2960-3150

Carlos E. Velasquez

ISSN 2359-1412/RBGAS-2020-0120/2021/8/18/15/235

Rev. Bras. Gest. Amb. Sustent.

http://revista.ecogestaobrasil.net 
electrical generation capacity. This study is carried out in two areas: one of $25 \mathrm{~km}^{2}$ comprehending the Muicipality of Figueira and another of $2,500 \mathrm{~km}^{2}$ in the vicinity of the plant. To calculate the socio-environmental impacts caused by the operation of the plant, SIMPACTS is used, which estimates and quantifies the costs of environmental and health damage due to the emissions of $\mathrm{SO}_{\mathrm{x}}$, $\mathrm{NO}_{\mathrm{x}}$ and particulate matter, $\mathrm{MP}_{10}$, in addition to showing its dispersion in the surroundings of the power plant. The impacts on Municipality of Figueira costs an average of US\$ 56.60/GWh, reaching a total of US\$127.60/GWh in the year of higher pollution. Taking into account the surrounding region $(2,500$ $\mathrm{km}^{2}$ ), the average cost of impacts from pollution increases to US\$ $4,475.50 /$ GWh, with a peak of US\$17,675.30/GWh, in 2017. The results show a disparity in socio-environmental impacts between the years of highest and lowest emission of pollutants, which may indicate that strict control of emissions can cause a significant reduction in them.

Keywords: Energy; Thermoelectric; Figueira; Pollution; Health; Coal.

\section{Introdução}

O uso da eletricidade favoreceu o desenvolvimento tecnológico e é imprescindível para manter atividades humanas básicas. Por consequência, cada vez mais a humanidade possui maior dependência dessa forma de energia. No entanto, a geração de energia elétrica deve ser estudada em função da curva de carga necessária para poder garantir seu suprimento de forma econômica e com menor prejuízo ambiental. Dentre as diferentes formas de geração de energia elétrica estão as renováveis e não renováveis, que de maneira mais ou menos intensa causam impactos adversos e consequentemente geram prejuízos à saúde humana e ao meio ambiente. Por exemplo, a usina termelétrica (UTE) a carvão mineral localizada no Município de Figueira, utiliza como combustível o carvão mineral do tipo CE-6000 com 29,8\% de cinzas, 3,2\% de enxofre e poder calorífico de 6.070 $\mathrm{kcal} / \mathrm{kg}$ (Gomes et al., 2003).

Dentre os processos que intensificam as mudanças climáticas, encontram-se as atividades antropogênicas responsáveis pelo aumento das emissões de gases do efeito estufa (GEE) nas últimas décadas que desequilibram as dinâmicas dos ecossistemas e prejudicam a saúde humana (Parry et al., 2007). Na geração de energia, as termelétricas de combustíveis fósseis têm maior contribuição na emissão de poluentes quando comparadas a outras formas mais sustentáveis de produção energética. No mundo a quantidade de energia elétrica gerada a partir de combustíveis fósseis, segundo a Empresa de Pesquisa Energética (EPE), é de 65,1\%, enquanto no Brasil a participação fóssil na geração elétrica é de 17,5\% (EPE, 2020).

Dentre os poluentes atmosféricos provenientes da geração térmica a base de combustíveis fósseis, destacam-se os óxidos nitrosos $\left(\mathrm{NO}_{\mathrm{x}}\right)$, dióxido de enxofre $\left(\mathrm{SO}_{2}\right)$ e material particulado (MP). Também são produzidos GEE, principalmente $\mathrm{CO}_{2}$ a partir da queima do combustível. Tais emissões, além de contribuírem para o aquecimento global, também provocam alterações na qualidade do ar, efeitos na saúde da população local e acidificação da água das chuvas (Tolmasquim, 2016).

Assim sendo, o Quarto Relatório de Avaliações das Mudanças Climáticas do Planeta (IPCC-AR4) (Parry et al., 2007), alerta com 90\% de confiabilidade que até 2100 a 
temperatura média terrestre aumentará entre $1,8{ }^{\circ} \mathrm{C}$ e $4{ }^{\circ} \mathrm{C}$, acarretando problemas como degelo das calotas polares, mudanças nas dinâmicas climáticas e perda de biodiversidade. De acordo com as estimativas anuais de emissões de gases de efeito estufa no Brasil (Brasil, 2017), no ano de 2014 a produção de energia foi responsável por 37\% das emissões de GEE. Este aumento das emissões está diretamente ligado ao crescimento das doenças respiratórias, que de acordo com o estudo da saúde Brasil 2018 (Brasil, 2019), do Ministério da Saúde, as mortes por doenças respiratórias crônicas não transmissíveis (DCNT) aumentaram em 14\% nos últimos dez anos.

Entre as usinas termelétricas a carvão no Brasil temos a UTE a carvão mineral, está localizada perto da maior bacia carbonífera do estado do Paraná. A configuração atual da usina é constituída de duas caldeiras PMTA $38 \mathrm{kgf} / \mathrm{cm}^{2}$, com vazão de vapor cerca de $50 \mathrm{t} / \mathrm{h}$, onde o carvão é queimado para gerar calor e transformar em vapor a água presente em tubos localizados na parede das caldeiras. Esse vapor em alta pressão aciona os dois geradores da termelétrica com potência de $10.000 \mathrm{~kW}$. Os principais poluentes que saem pela chaminé são $\mathrm{NOx}, \mathrm{SO}_{2}$ e MP que são extremamente danosos à saúde humana e podem gerar danos na agricultura, por exemplo, feijões expostos a poluição atmosférica tendem a crescer menos (Apro et al., 2012).

Portanto, o presente estudo busca investigar sobre as emissões de poluentes da UTE em Figueira e os efeitos produzidos à saúde. Procura de dados técnicos sobre a usina termelétrica a carvão localizada no Município de Figueira. Analisar a distribuição populacional ao redor da UTE assim como da distribuição de agricultura ao redor da usina. Introdução dos possíveis impactos à saúde que podem ser ocasionados pelos poluentes $\mathrm{SO}_{2}, \mathrm{SO}_{4}, \mathrm{NO}_{\mathrm{x}}$ e MP10 emitidos pela UTE.

\section{Metodologia}

Os impactos socioambientais causados pela operação da UTE foram quantificados considerando dois casos, uma área de estudo de $5 \mathrm{~km} \times 5 \mathrm{~km}\left(25 \mathrm{~km}^{2}\right)$ e posteriormente $50 \mathrm{~km} \times 50 \mathrm{~km}\left(2.500 \mathrm{~km}^{2}\right)$. 0 período considerado inicia-se em 2004, devido à disponibilidade dos dados sobre emissão, até 2018. O Simplified Approach of Estimating Impacts of Electricity Generation (SIMPACTS) (IAEA, 2020) utiliza os dados demográficos e técnicos da usina para poder quantificar os danos à saúde ao redor da UTE de carvão mineral devido à atividade de geração de energia elétrica, trabalhos similares foram realizados em outros países usando o SIMPACTS (Hainoun et al., 2010; Nwanya, 2011; Fard et al., 2016; Jorli et al., 2017), no Brasil existem estudos similares em relação aos impactos ambientais causados pela poluição de termelétricas (Hoffmann, 2013; Almeida et al., 2019; Pedruzzi et al., 2019).

Tabela 1. Características UTE.

\begin{tabular}{|l|c|}
\hline Altitude de UTE & $593 \mathrm{~m}$ \\
\hline Altitude da chaminé & $40 \mathrm{~m}$ \\
\hline Diâmetro chaminé & $4 \mathrm{~m}$ \\
\hline Temperatura de saída do vapor & $723 \mathrm{k}$ \\
\hline Velocidade de saída do vapor & $10 \mathrm{~m} / \mathrm{s}$ \\
\hline Combustível & Carvão mineral \\
\hline Início das operações & 1963 \\
\hline Coordenadas geográficas & $23^{\circ} 51^{\prime} 09,0^{\prime \prime} \mathrm{S}-50^{\circ} 23^{\prime} 25,7^{\prime \prime} \mathrm{W}$ \\
\hline
\end{tabular}

Fonte: Rohde e Machado (2016), Carbonífera Cambuí (2020) e Boz Neto (2013). 
A UTE a carvão mineral encontra-se instalada no Município de Figueira, no Estado do Paraná, sul do Brasil, que, de acordo com o IBGE (2010) possui uma área de 129,769 $\mathrm{km}^{2}$, com população de 8.293 habitantes e densidade demográfica de $63,91 \mathrm{hab} / \mathrm{km}^{2}$. Os dados técnicos necessários da usina termelétrica (UTE) a carvão mineral para realizar o estudo são apresentados na Tabela 1.

\section{Características demográficas}

Para obter a densidade populacional da área em estudo, delimitou-se uma região de $25 \mathrm{~km}^{2}$, tendo a chaminé da usina como ponto central. A área foi dividida em uma matriz 41 x 41, resultando em 1.681 quadrantes; processo feito no AutoCad (Autodesk, 2020). Dessa maneira, a estimativa populacional foi feita em cada quadrante da matriz, relacionando o número de casas com a densidade demográfica. A Figura 1 representa a área delimitada do estudo para uma região de $25 \mathrm{~km}^{2}$.

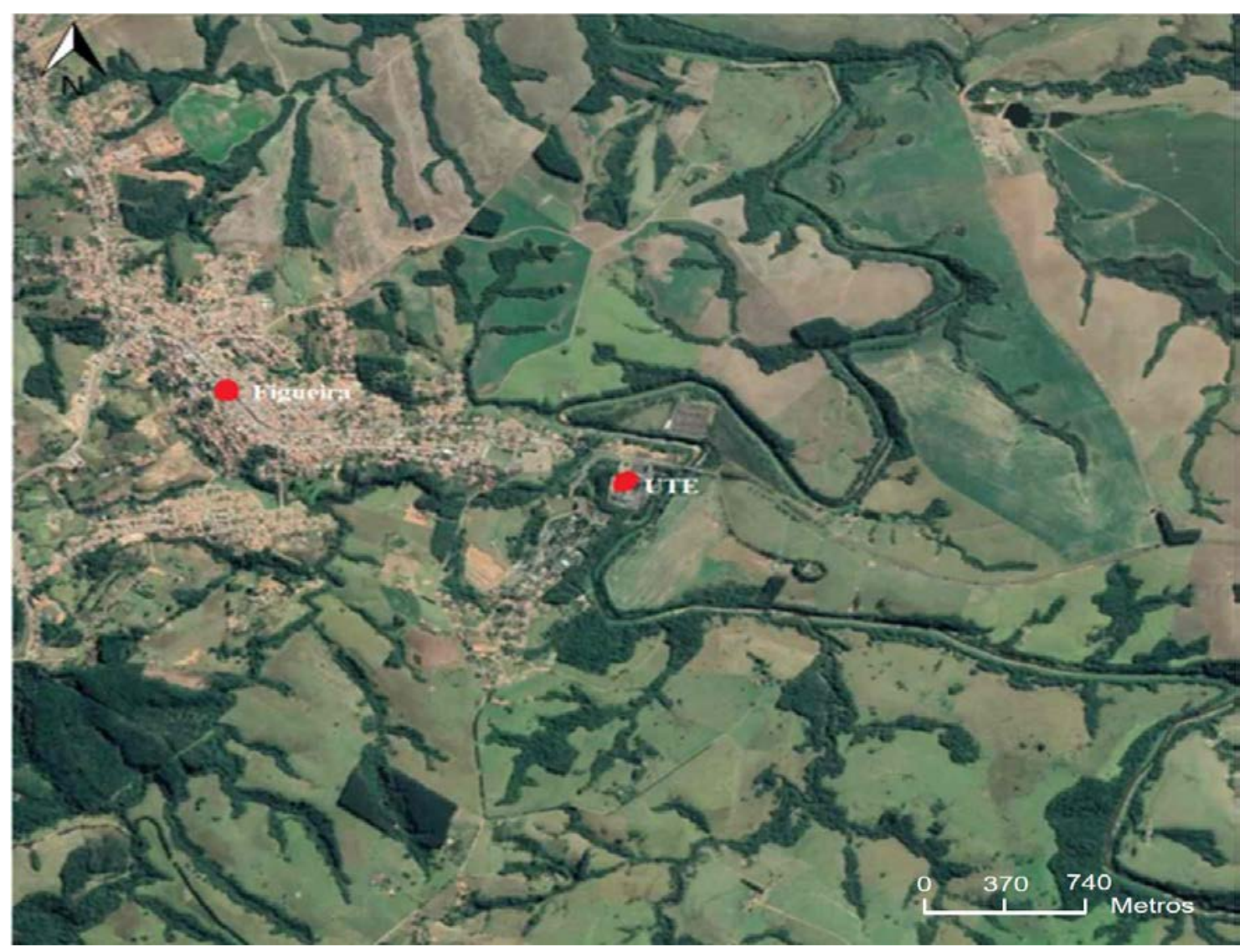

Figura 1. Área no entorno da UTE: escala 5 km. Fonte: Google Earth.

A mesma metodologia foi aplicada para determinar a densidade populacional na área de $2.500 \mathrm{~km}^{2}$ (50 km x $50 \mathrm{~km}$ ). Esta área está representada na Figura 2. Com o aumento da área, novos municípios são englobados no estudo, dentre eles temos Sapopema (6.736 habitantes), Ibaiti (31.364 habitantes), Curiúva (15.101 habitantes) e Campinho, Região Metropolitana de Ibaiti (IBGE, 2010).

Para delimitar a produção agrícola utilizou-se a mesma metodologia de separação por quadrantes. A área plantada observada em cada quadrante foi medida em metros quadrados usando o AutoCad. A produção agrícola total das cidades foi obtida segundo dados do IBGE (2010). 


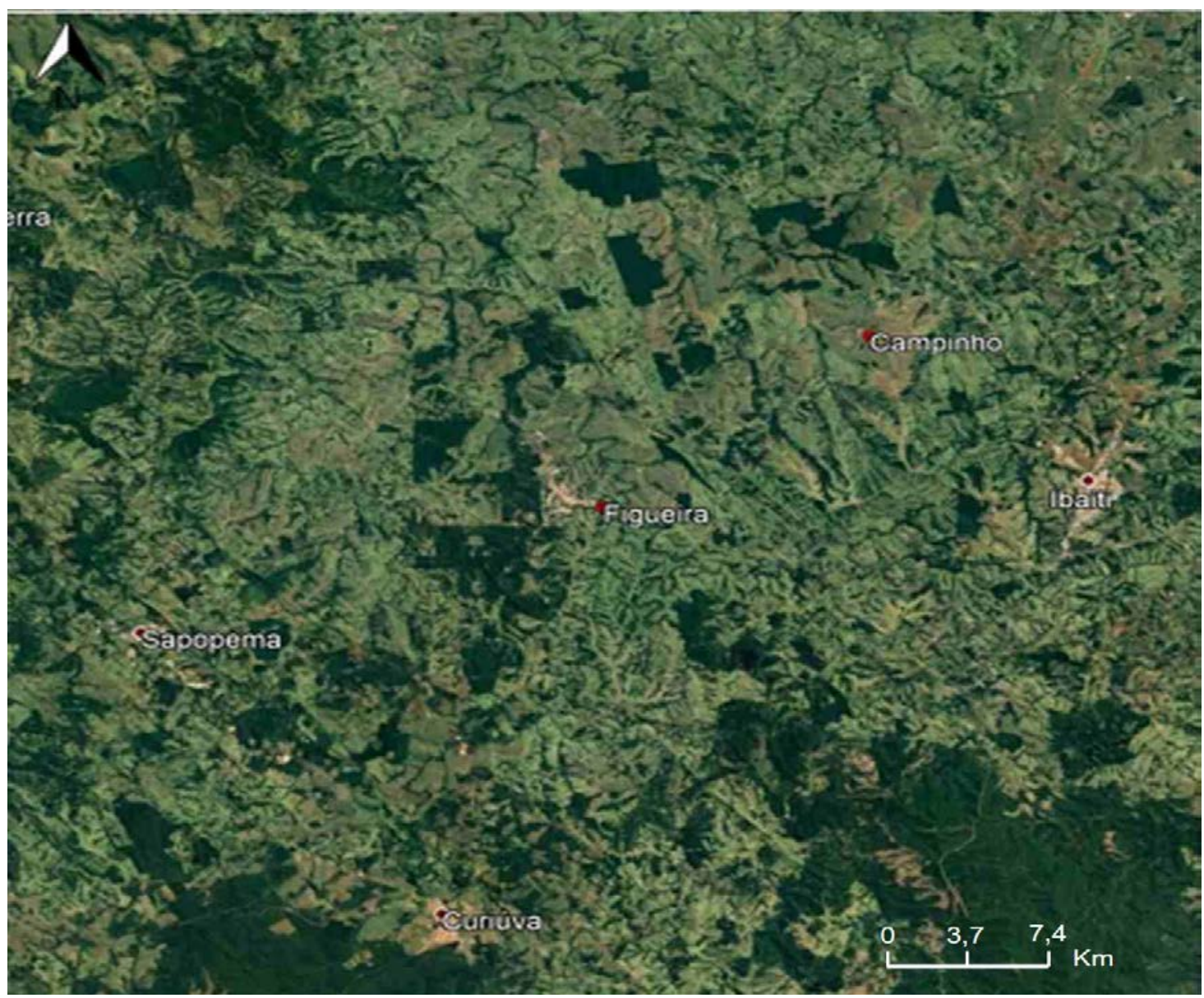

Figura 2. Área no entorno da UTE: escala 25 km. Fonte: Google Earth.

\section{Emissão de poluentes}

Os dados das emissões de $\mathrm{NO}_{x}, \mathrm{SO}_{2}$, $\mathrm{MP}$ e $\mathrm{CO}_{2}$ foram obtidos nos relatórios de sustentabilidade emitidos anualmente pela Companhia Paranaense de Energia (COPEL), responsável pela operação de UTE a carvão mineral (COPEL, 2004, 2005, 2006, 2007, 2008, 2009, 2010, 2011, 2012, 2013, 2014, 2015, 2016, 2017, 2018). Os dados sobre material particulado só começaram a ser disponibilizados a partir de 2011, dessa maneira, para obter resultados completos no SIMPACTS foram calculadas as médias de todas as emissões de material particulado informadas entre 2011 e 2018, retirando os dois anos com maior e menor emissão devido a sua disparidade se comparado com os demais resultados. Esse valor médio foi atribuído aos anos de 2004 a 2010, portanto as emissões de MP durante esses anos são iguais.

Os dados de COPEL $(2004,2005,2006,2007,2008,2009,2010,2011,2012,2013$, 2014, 2015, 2016, 2017, 2018)), referentes à emissão de poluentes atmosféricos da UTE a carvão mineral, são disponibilizados de forma anual, porém devido à necessidade dos dados em unidades mensais utilizou-se o histórico de operação da ONS (2020) para conversão dos dados por meio da equação 1 :

$$
E m=(E t * G W m) / G W t
$$

Onde $E m=$ Emissão no mês; $E t=$ emissão total no ano; $G W m=$ energia gerada no mês e $G W t=$ energia total do ano. 
Por fim, o SIMPACTS calcula o dano gerado pela usina levando em consideração o número de pessoas que ficaram doentes em virtude das atividades da UTE e apresenta um custo relacionado a cada doença já estabelecido no programa, as enfermidades consideradas pelo modelo são:

- Mortalidade crônica - População inteira;

- Mortalidade infantil - Menores de 12 meses;

- Mortalidade aguda - População inteira;

- Uso de broncodilatador - Asma adultos maiores de 20 anos;

- Uso de broncodilatador - Asma criança de 5 a 14 anos;

- Dificuldade respiratória - Adultos com dificuldade respiratória crônica;

- Dificuldade respiratória - Crianças de 5-14 anos;

- Restrição de atividades diárias - Adultos que trabalham, de 15-64 anos;

- Restrição de atividades diárias - Adultos que não trabalham, de 15-64 anos;

- Internação cardíaca - População inteira;

- Internação por problemas respiratórios - População inteira;

- Bronquite crônica - Adultos maiores de 27 anos.

\section{Resultados}

Os dados de geração de energia elétrica da UTE a carvão mineral para o período de 2004 a 2018, segundo o Operador Nacional do Sistema Elétrico (NOS, 2020), são apresentados na Figura 3. Pode-se perceber que a geração de energia da UTE se manteve quase constante durante os 14 anos. Apenas em 2018 é possível observar uma queda na geração de energia, pois a usina parou de operar em julho devido a reformas que visavam melhora na eficiência da UTE.

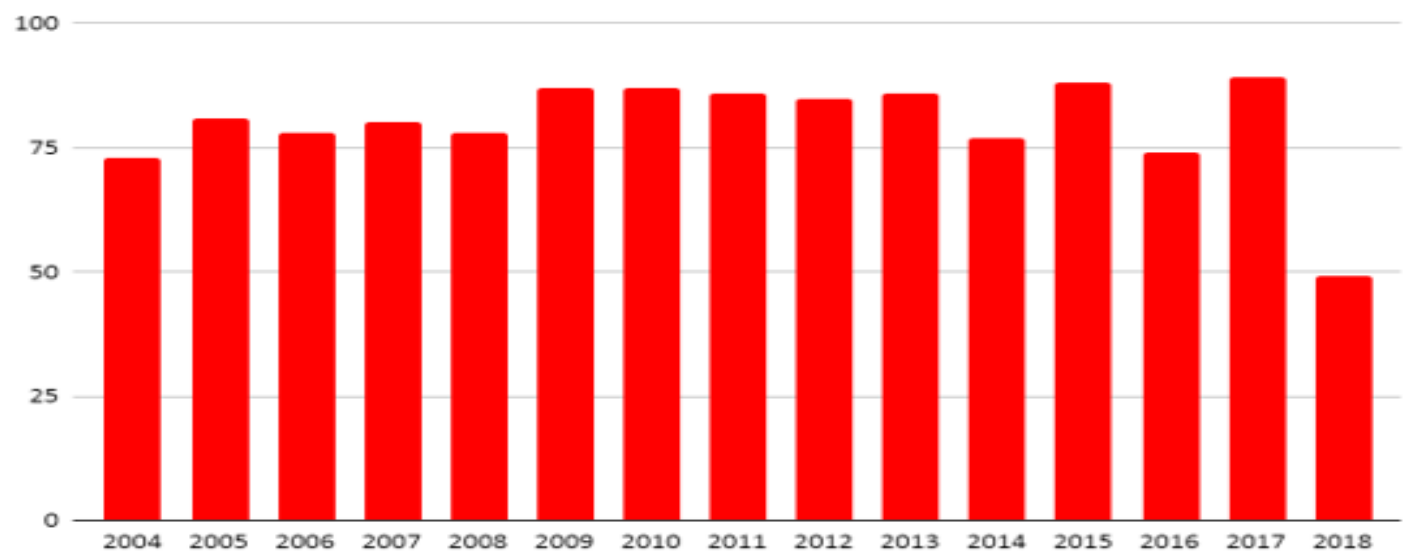

Figura 3. Geração de energia elétrica da UTE (Figueira). Fonte: (ONS, 2020).

A Figura 4 mostra a distribuição da população, representada após a inserção da matriz populacional no SIMPACTS, para a área de $25 \mathrm{~km}^{2}$ no entorno da UTE que se encontra no município de Figueira. 0 ponto no centro na imagem representa a localização da UTE. Dessa forma, o número de pessoas que estão na área de estudo é de 7.492 , cerca 
de $90 \%$ da população residente de Figueira. Devido à localização da UTE próxima ao centro comercial/residencial da cidade, grande parte da população é atingida.

A estimativa da distribuição da população na área de $2.500 \mathrm{~km}^{2}$ é apresentada na Figura 5. É possível observar uma maior concentração de pessoas justamente nas regiões onde as áreas urbanas dos municípios se encontram. 0 total de pessoas atingidas estimadas foi de cerca de 80.000 , junção de todos os municípios englobados por completo, mais parte de outros centros urbanos como Jaboti.
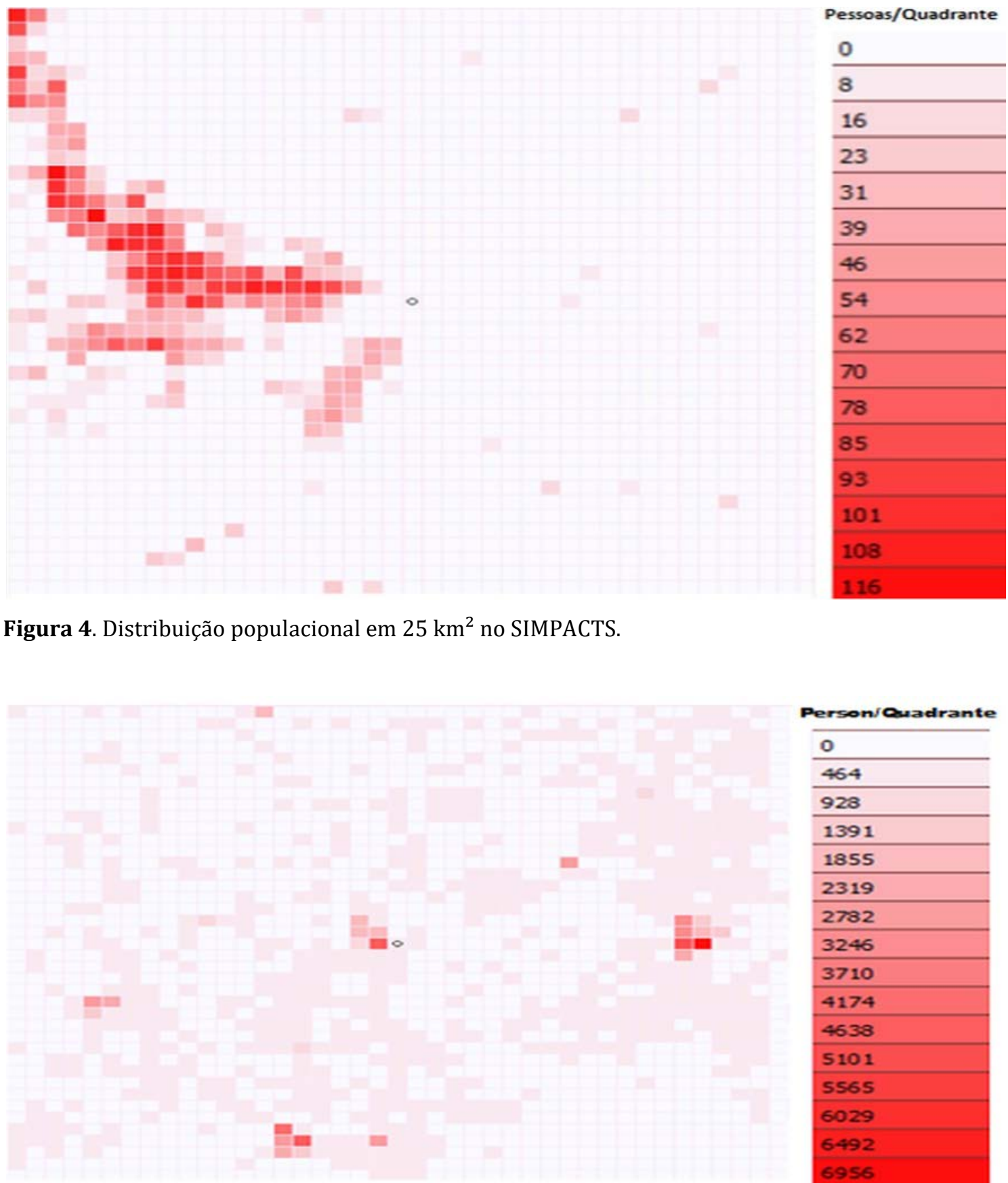

Figura 4. Distribuição populacional em $25 \mathrm{~km}^{2}$ no SIMPACTS.

Figura 5. Distribuição populacional em $2.500 \mathrm{~km}^{2}$ no SIMPACTS.

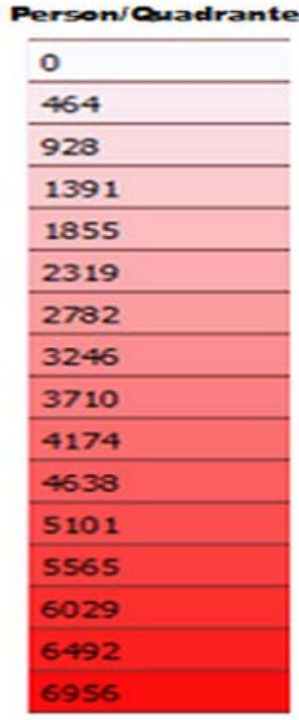

Rev. Bras. Gest. Amb. Sustent., 2021, vol. 8, n. 18, p. 235-263. 
Com os dados da área plantada $\left(\mathrm{m}^{2}\right)$ e da produção agrícola $(\mathrm{t})$, estimou-se a produção agrícola por metro quadrado (Tabela 2).

Tabela 2. Produção agrícola dos municípios afetados.

\begin{tabular}{|c|c|c|c|c|}
\hline Tipo de cultura & $\begin{array}{c}\text { Figueira } \\
\left(t / \mathrm{m}^{2}\right)\end{array}$ & $\begin{array}{c}\text { Ibaiti } \\
\left(t / \mathrm{m}^{2}\right)\end{array}$ & $\begin{array}{c}\text { Sapopema } \\
\left(t / m^{2}\right)\end{array}$ & $\begin{array}{c}\text { Curiúva } \\
\left(t / m^{2}\right)\end{array}$ \\
\hline Alho & $5,00 \times 10^{-4}$ & - & - & $4,00 \times 10^{-4}$ \\
\hline Amendoim & $1,75 \times 10^{-4}$ & $2,00 \times 10^{-4}$ & - & $1,75 \times 10^{-4}$ \\
\hline Arroz & $1,50 \times 10^{-4}$ & $1,80 \times 10^{-4}$ & $2,20 \times 10^{-4}$ & $1,50 \times 10^{-4}$ \\
\hline Batata doce & $1,25 \times 10^{-3}$ & - & - & - \\
\hline Cana de açúcar & $6,25 \times 10^{-3}$ & - & - & $5,00 \times 10^{-3}$ \\
\hline Cebola & $1,80 \times 10^{-3}$ & - & - & $2,00 \times 10^{-3}$ \\
\hline Ervilha & $4,00 \times 10^{-4}$ & - & - & - \\
\hline Feijão & $9,62 \times 10^{-5}$ & $9,88 \times 10^{-5}$ & $1,09 \times 10^{-4}$ & $8,93 \times 10^{-5}$ \\
\hline Mandioca & $2,00 \times 10^{-3}$ & - & $2,10 \times 10^{-3}$ & $2,30 \times 10^{-3}$ \\
\hline Melancia & $2,00 \times 10^{-3}$ & - & - & - \\
\hline Milho & $2,42 \times 10^{-4}$ & $2,95 \times 10^{-4}$ & $8,88 \times 10^{-4}$ & $4,47 \times 10^{-4}$ \\
\hline Soja & $3,00 \times 10^{-4}$ & $3,10 \times 10^{-4}$ & $3,24 \times 10^{-4}$ & $3,70 \times 10^{-4}$ \\
\hline Tomate & $7,00 \times 10^{-3}$ & - & $4,60 \times 10^{-3}$ & $6,85 \times 10^{-3}$ \\
\hline Trigo & $1,56 \times 10^{-4}$ & $2,20 \times 10^{-4}$ & $2,79 \times 10^{-4}$ & $2,50 \times 10^{-4}$ \\
\hline Total & $3,00 \times 10^{-4}$ & $2,48 \times 10^{-4}$ & $3,09 \times 10^{-4}$ & $4,44 \times 10^{-4}$ \\
\hline
\end{tabular}

Fonte: Adaptado de (IBGE, 2010).

As emissões mensais de poluentes de 2017 e 2008 (anos com maior e menor emissão de poluentes no período) são apresentadas nas Tabelas 3 e 4, respectivamente.

Tabela 3. Emissões e geração 2017.

\begin{tabular}{|l|c|c|c|c|c|}
\hline $\mathbf{2 0 1 7}$ & $\mathbf{M P}_{\mathbf{1 0}}(\mathbf{t})$ & NOx (t) & SOx (t) & $\mathbf{C O}_{\mathbf{2}}$ (t) & $\begin{array}{c}\text { Geração } \\
\text { (GWh) }\end{array}$ \\
\hline Janeiro & 21,79 & 197,42 & $1.206,83$ & $17.582,92$ & 7 \\
\hline Fevereiro & 6,22 & 56,40 & 344,81 & $5.023,69$ & 2 \\
\hline Março & 18,67 & 169,21 & $1.034,43$ & $15.071,08$ & 6 \\
\hline Abril & 28,01 & 253,82 & $1.551,64$ & $22.606,61$ & 9 \\
\hline Maio & 28,01 & 253,82 & $1.551,64$ & $22.606,61$ & 9 \\
\hline Junho & 28,01 & 253,82 & $1.551,64$ & $22.606,61$ & 9 \\
\hline Julho & 28,01 & 253,82 & $1.551,64$ & $22.606,61$ & 9 \\
\hline Agosto & 28,01 & 253,82 & $1.551,64$ & $22.606,61$ & 9 \\
\hline Setembro & 28,01 & 253,82 & $1.551,64$ & $22.606,61$ & 9 \\
\hline Outubro & 28,01 & 253,82 & $1.551,64$ & $22.606,61$ & 9 \\
\hline Novembro & 21,79 & 197,42 & $1.206,83$ & $17.582,92$ & 7 \\
\hline Dezembro & 12,45 & 112,81 & 689,62 & $10.047,38$ & 4 \\
\hline Total (t) & 277,00 & $2.510,00$ & $15.344,00$ & $223.554,26$ & 89 \\
\hline
\end{tabular}

Fonte: ONS (2020) e COPEL (2017). 
Tabela 4. Emissões e geração 2008.

\begin{tabular}{|l|c|c|c|c|c|}
\hline $\mathbf{2 0 0 8}$ & $\mathbf{M P}_{\mathbf{1 0}}(\mathbf{t})$ & NOx (t) & SOx (t) & $\mathbf{C O}_{\mathbf{2}}(\mathbf{t})$ & $\begin{array}{c}\text { Geração } \\
\text { (GWh) }\end{array}$ \\
\hline Janeiro & 26,26 & 35,38 & 180,51 & $20.777,31$ & 10 \\
\hline Fevereiro & 23,63 & 31,85 & 162,46 & $18.699,58$ & 9 \\
\hline Março & 15,76 & 21,23 & 108,31 & $12.466,38$ & 6 \\
\hline Abril & 2,63 & 3,54 & 18,05 & $2.077,73$ & 1 \\
\hline Maio & 13,13 & 17,69 & 90,26 & $10.388,65$ & 5 \\
\hline Junho & 15,76 & 21,23 & 108,31 & $12.466,38$ & 6 \\
\hline Julho & 15,76 & 21,23 & 108,31 & $12.466,38$ & 6 \\
\hline Agosto & 15,76 & 21,23 & 108,31 & $12.466,38$ & 6 \\
\hline Setembro & 18,38 & 24,77 & 126,36 & $14.544,12$ & 7 \\
\hline Outubro & 18,38 & 24,77 & 126,36 & $14.544,12$ & 7 \\
\hline Novembro & 18,38 & 24,77 & 126,36 & $14.544,12$ & 7 \\
\hline Dezembro & 21,01 & 28,31 & 144,41 & $16.621,85$ & 8 \\
\hline Total (t) & 204,84 & 276,00 & $1.408,01$ & $162.063,00$ & 78 \\
\hline
\end{tabular}

Fonte: ONS (2020) e COPEL (2008).

A Figura 6 relaciona a emissão de poluentes $\left(\mathrm{NO}_{\mathrm{x}}, \mathrm{SO}_{\mathrm{x}}\right.$ e $\left.\mathrm{MP}\right)$ com a geração de energia do ano em questão. Dessa maneira, é possível analisar que as atividades na usina são constantes durante os anos, tendo pequenas variações na geração de energia, contudo as emissões oscilam consideravelmente durante os anos. No relatório de sustentabilidade de 2007 a COPEL implementou o Programa de Gestão Corporativa de Gases de Efeito Estufa (PGCMC), o qual possuía os seguintes objetivos (COPEL, 2007):

- Inventariar as emissões de gases de efeito estufa no âmbito da COPEL;

- Avaliar e propor mecanismos de redução/neutralização de emissões pela Companhia;

- Identificar e encaminhar novas oportunidades de projetos com potencial para qualificação no âmbito do Mecanismo de Desenvolvimento Limpo - MDL;

- Criar ferramentas internas de compensação;

- Incentivar inovação em tecnologia e processos, com foco na redução de emissões;

- Prestar apoio à continuidade relativamente a potenciais projetos identificados.

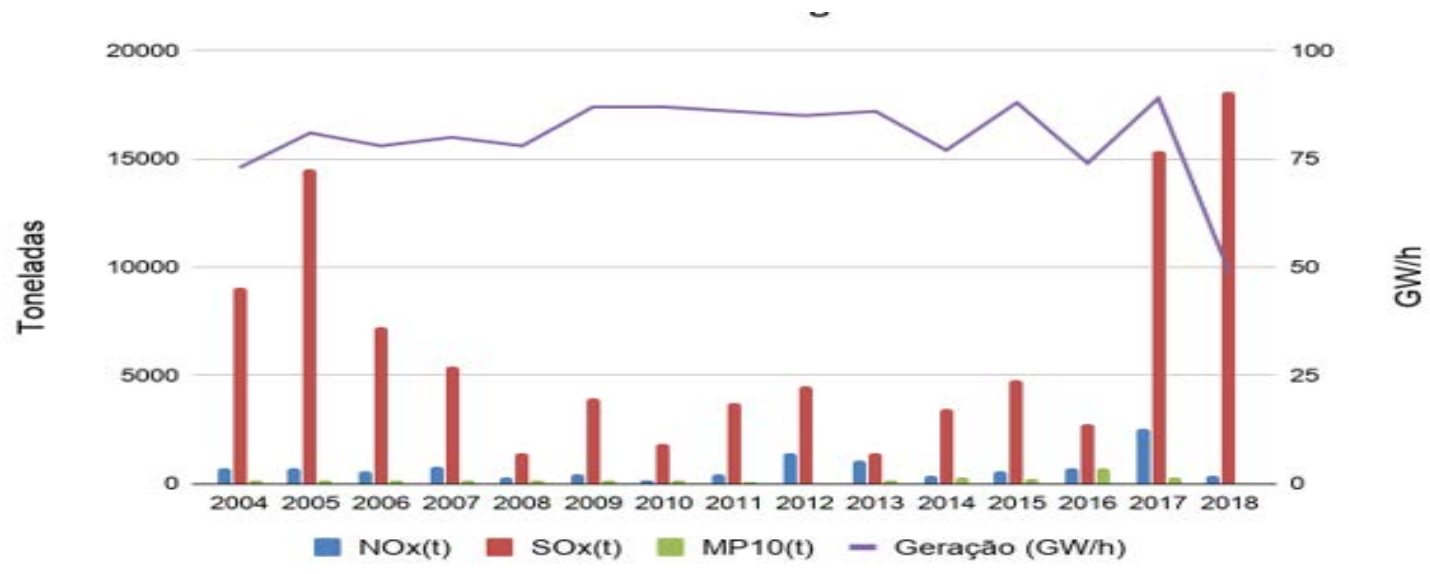

Figura 6. Emissões de poluentes versus geração de energia. 
Tabela 5. Emissões por geração.

\begin{tabular}{|c|c|c|c|c|}
\hline & NOx (t) & SOx (t) & MP $_{\mathbf{1 0}}$ (t) & Geração (GWh) \\
\hline 2004 & 704,65 & $9.051,12$ & 186,78 & 73,00 \\
\hline 2005 & 716,00 & $14.510,00$ & 186.78 & 81,00 \\
\hline 2006 & 591,00 & $7.243,37$ & 186,78 & 78,00 \\
\hline 2007 & 807,00 & $5.400,00$ & 186,78 & 80,00 \\
\hline 2008 & 276,00 & $1.408,00$ & 186,78 & 78,00 \\
\hline 2009 & 414,00 & 3,91 & 186,00 & 87,00 \\
\hline 2010 & 141,00 & $1.822,00$ & 186,78 & 87,00 \\
\hline 2011 & 437,40 & $3.721,30$ & 77,40 & 86,00 \\
\hline 2012 & 1410,00 & $4.510,00$ & 17,50 & 85,00 \\
\hline 2013 & 1075,00 & $1.420,71$ & 179.70 & 86,00 \\
\hline 2014 & 368,20 & $3.458,20$ & 261,00 & 77,00 \\
\hline 2015 & 583,00 & $4.797,00$ & 229,00 & 88,00 \\
\hline 2016 & 709,00 & $2.764,00$ & 709,00 & 74,00 \\
\hline 2017 & 2510,00 & $15.344,00$ & 277,00 & 89,00 \\
\hline 2018 & 336,00 & $18.108,00$ & 34,00 & 49,00 \\
\hline
\end{tabular}

Fonte: ONS (2020) e COPEL (2004, 2005, 2006, 2007, 2008, 2009, 2010, 2011, 2012, 2013, 2014, $2015,2016,2017,2018)$.

Esses esforços foram eficientes e diminuíram consideravelmente as emissões da usina a partir do ano de 2007 mantendo a mesma geração de energia, mas com uma menor emissão de poluentes atmosféricos. Como é possível observar na Tabela 5 e Figura 6, os níveis de emissão no início da década são consideravelmente maiores, apenas em 2017 os índices voltaram a crescer.

\section{Região de $25 \mathbf{k m}^{2}$ para o ano com menor poluição}

As Figuras 7-10 apresentam as dispersões das emissões de: $\mathrm{NO}_{\mathrm{x}}, \mathrm{MP}_{10}, \mathrm{SO}_{2}$ e $\mathrm{SO}_{4}$ no entorno da UTE localizada no município de Figueira para a área de $25 \mathrm{~km}^{2}$. As dispersões dos gases tendem a seguir o fluxo do vento predominantemente oeste e sul, portanto é possível observar as maiores concentrações nesse sentido, em microgramas por metro cúbico. Nesta área de estudo é possível observar os danos apenas na cidade de Figueira. A Figura 10 mostra a dispersão do $\mathrm{SO}_{4}$ em todo o entorno da usina, mas com maior alcance na direção sudoeste, como é possível observar nas imagens a seguir. A dispersão de $\mathrm{SO}_{4}$ é maior em relação aos similares. 


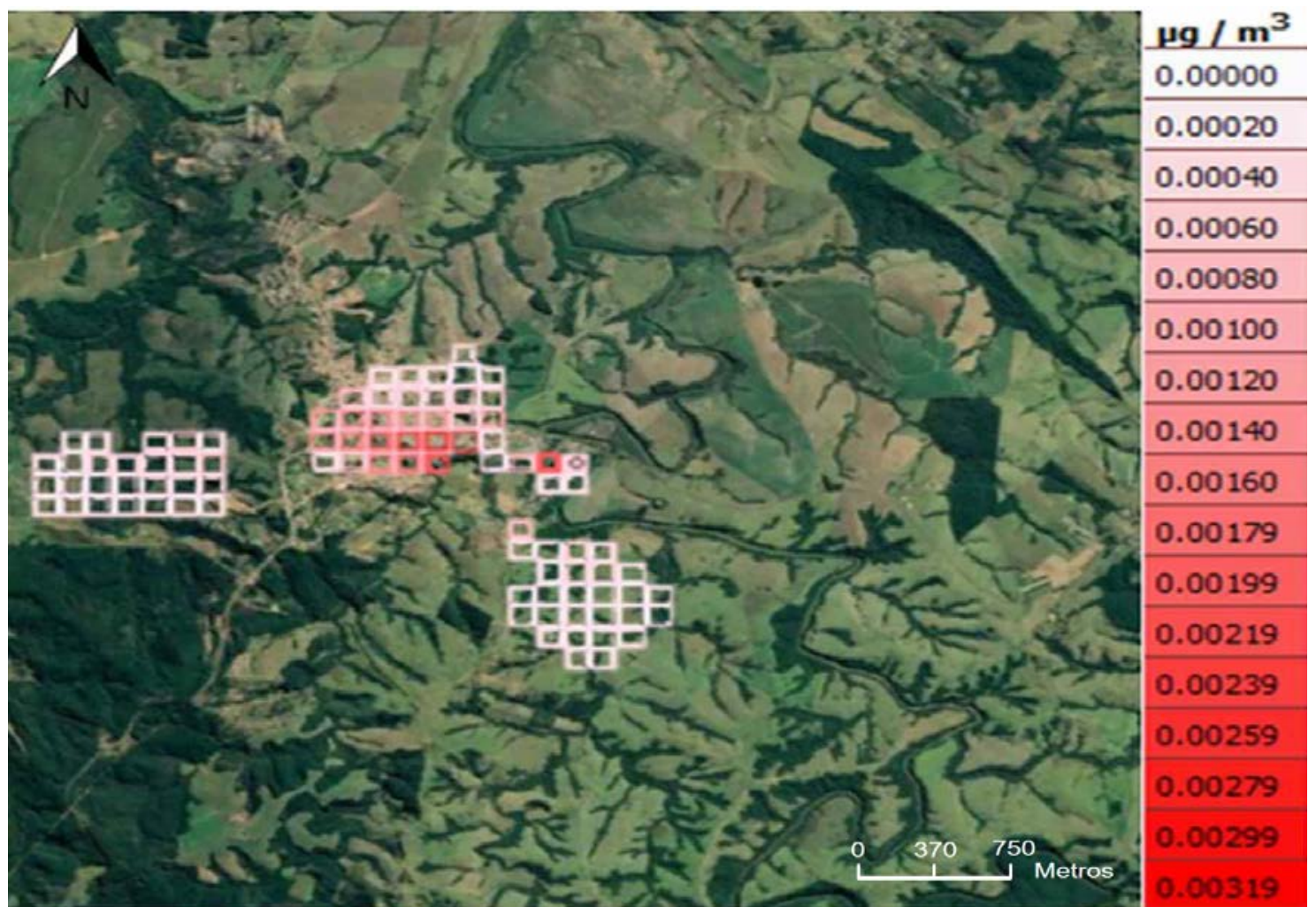

Figura 7. Dispersão de NOx em abril de 2008 no SIMPACTS. Fonte: Google Earth.

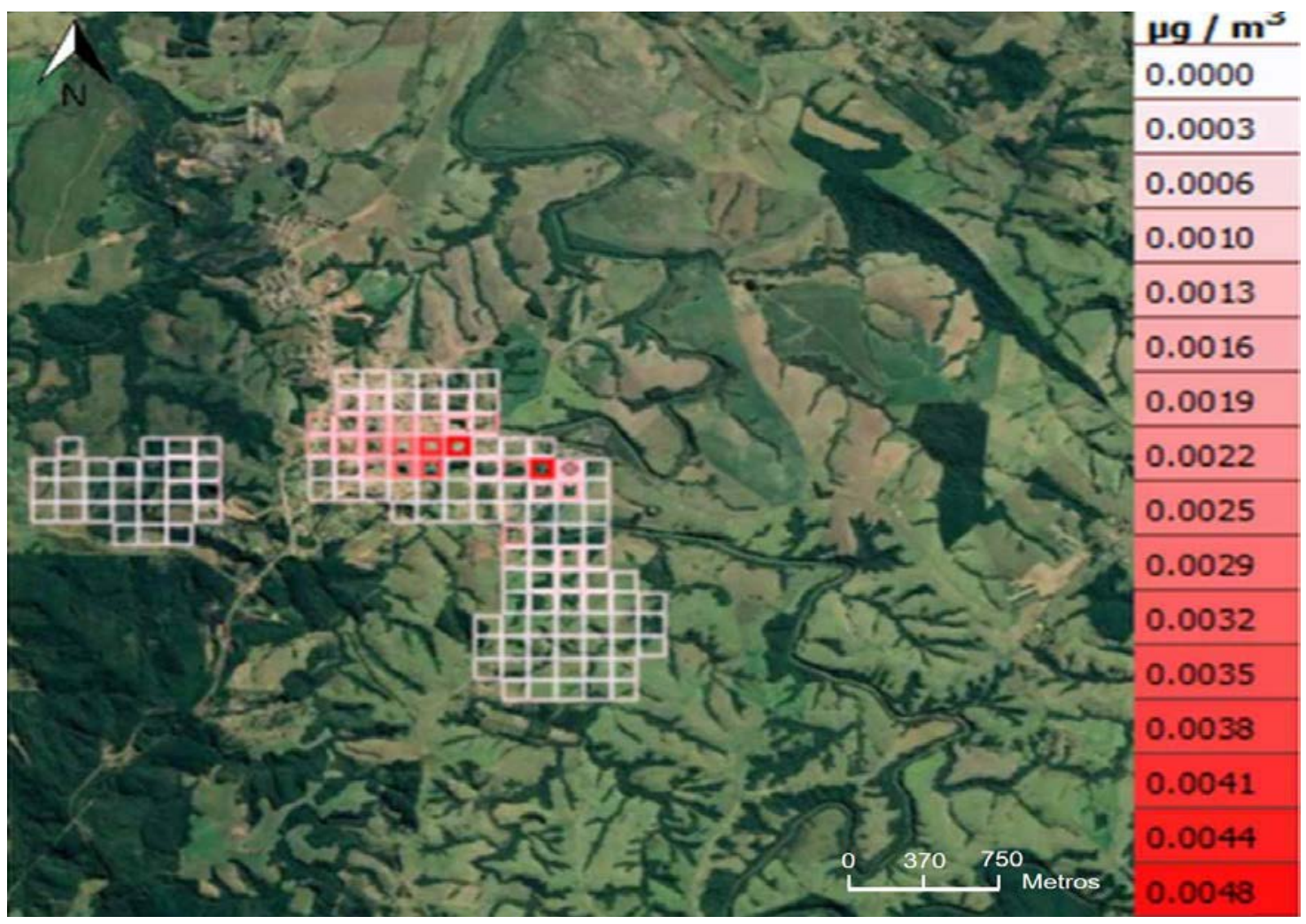

Figura 8. Dispersão de $\mathrm{MP}_{10}$ em abril de 2008 no SIMPACTS. Fonte: Google Earth. 


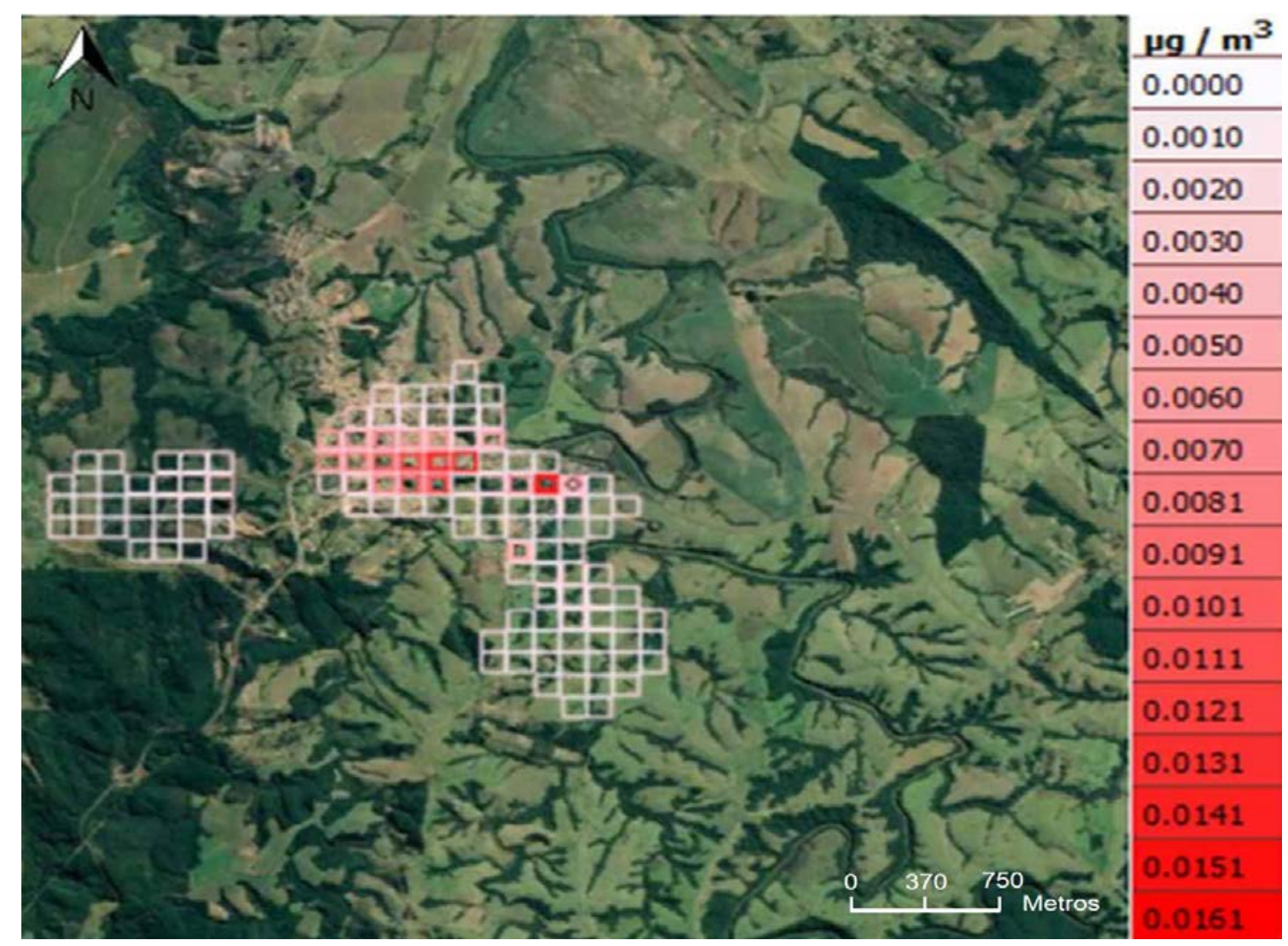

Figura 9. Dispersão $\mathrm{SO}_{2}$ em abril de 2008 no SIMPACTS. Fonte: Google Earth.

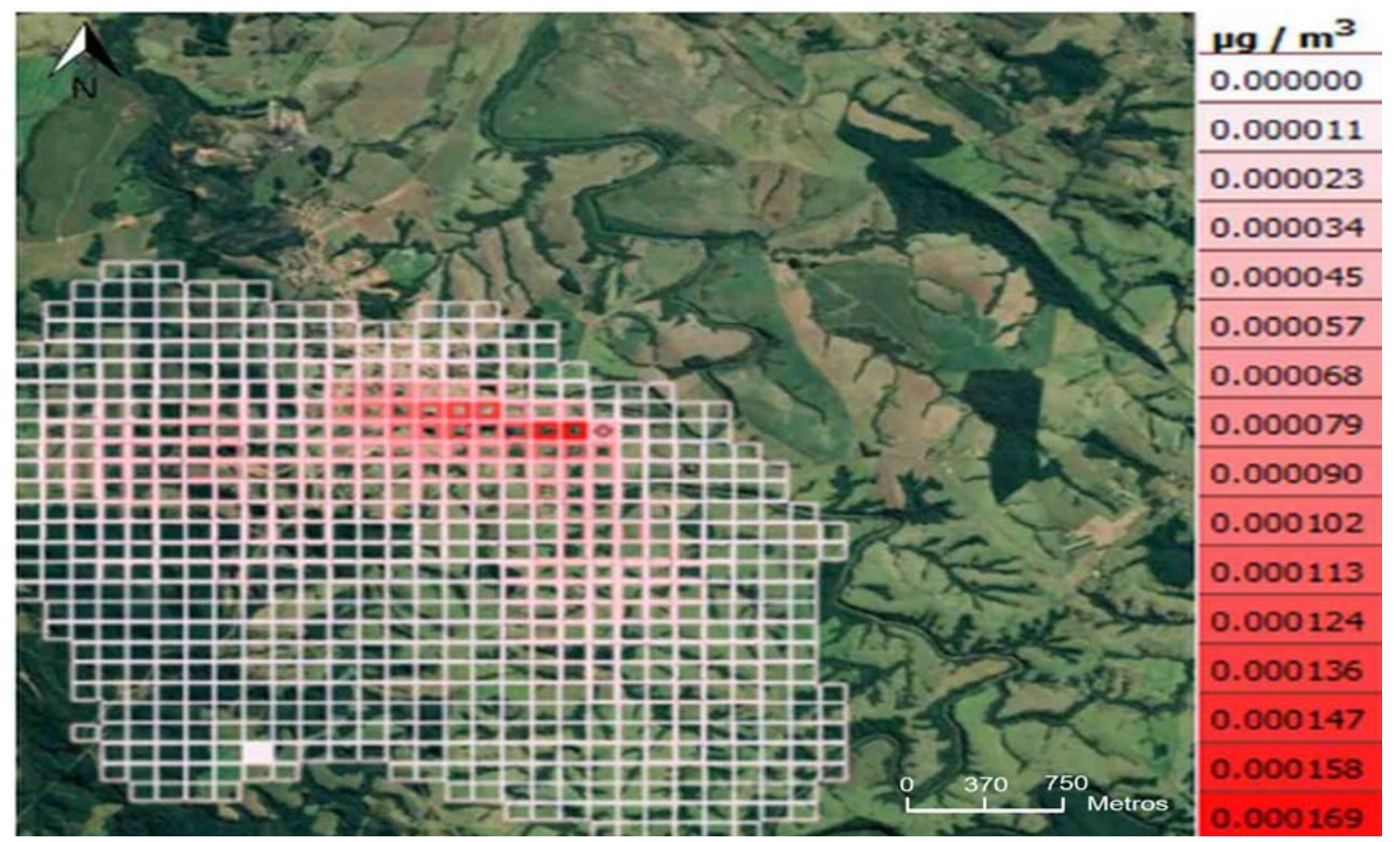

Figura 10. Dispersão $\mathrm{SO}_{4}$ em abril de 2008 no SIMPACTS. Fonte: Google Earth. 


\section{Região de $25 \mathbf{~ k m}^{2}$ para o ano com maior poluição}

As Figuras 11-14 mostram a dispersão dos gases para o ano de 2017 no mês de junho, ano com maior quantidade de poluentes emitidos pela UTE a carvão mineral. Neste ano pode-se perceber que região sudoeste foi a mais afetada pelos poluentes $\mathrm{SO}_{2}, \mathrm{NO}_{\mathrm{x}} \mathrm{e}$ MP, tomando como referência a UTE no centro. No entanto, a dispersão por $\mathrm{SO}_{4}$ apresenta conjuntamente com a dispersão em direção à região sul-oeste e nordeste.

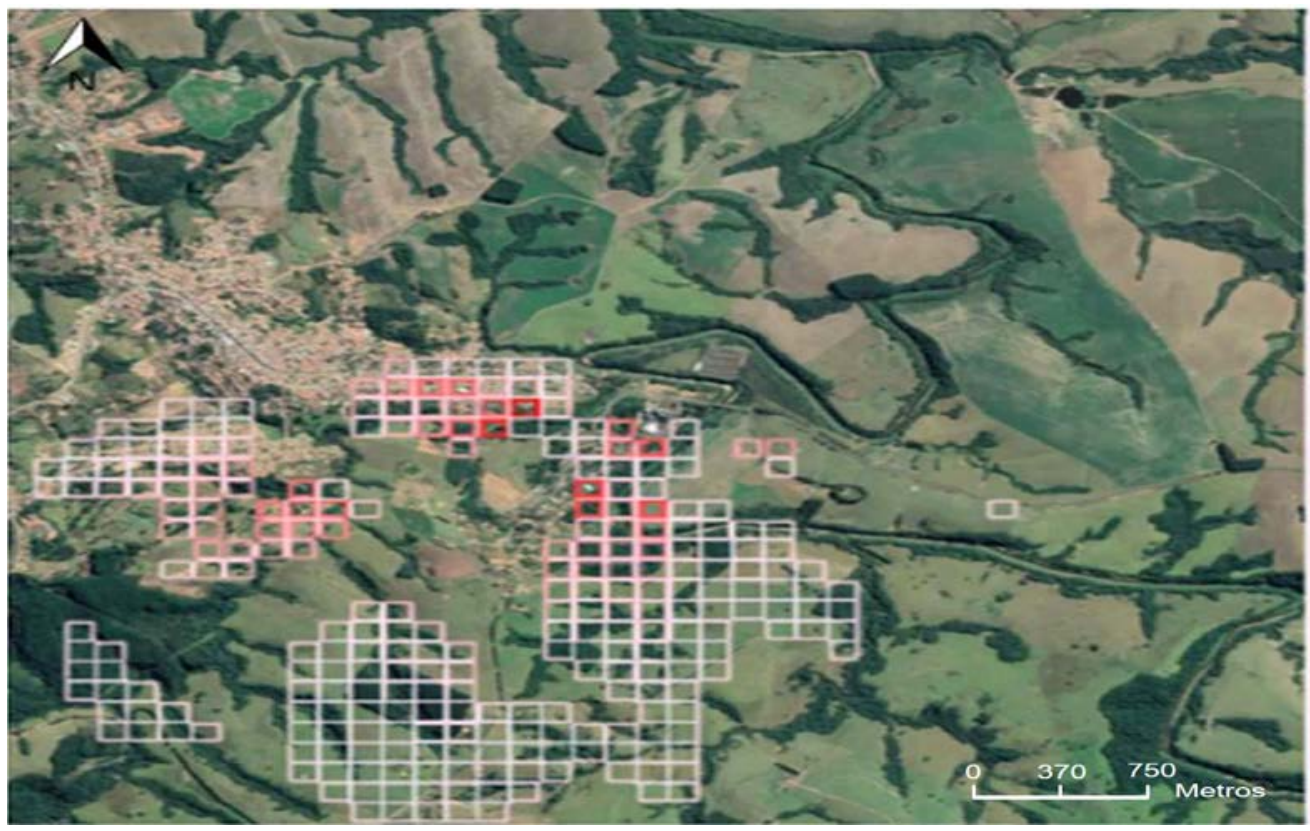

\begin{tabular}{l}
\hline $\mathbf{\mu g} / \mathrm{m}^{\Xi}$ \\
\hline 0.000 \\
\hline 0.007 \\
\hline 0.014 \\
\hline 0.021 \\
\hline 0.028 \\
\hline 0.035 \\
\hline 0.042 \\
\hline 0.049 \\
\hline 0.056 \\
\hline 0.062 \\
\hline 0.069 \\
\hline 0.076 \\
\hline 0.083 \\
\hline 0.090 \\
\hline 0.097 \\
\hline 0.104 \\
\hline
\end{tabular}

Figura 11. Dispersão de $\mathrm{NO}_{\mathrm{x}}$ em junho de 2017 no SIMPACTS. Fonte: Google Earth.

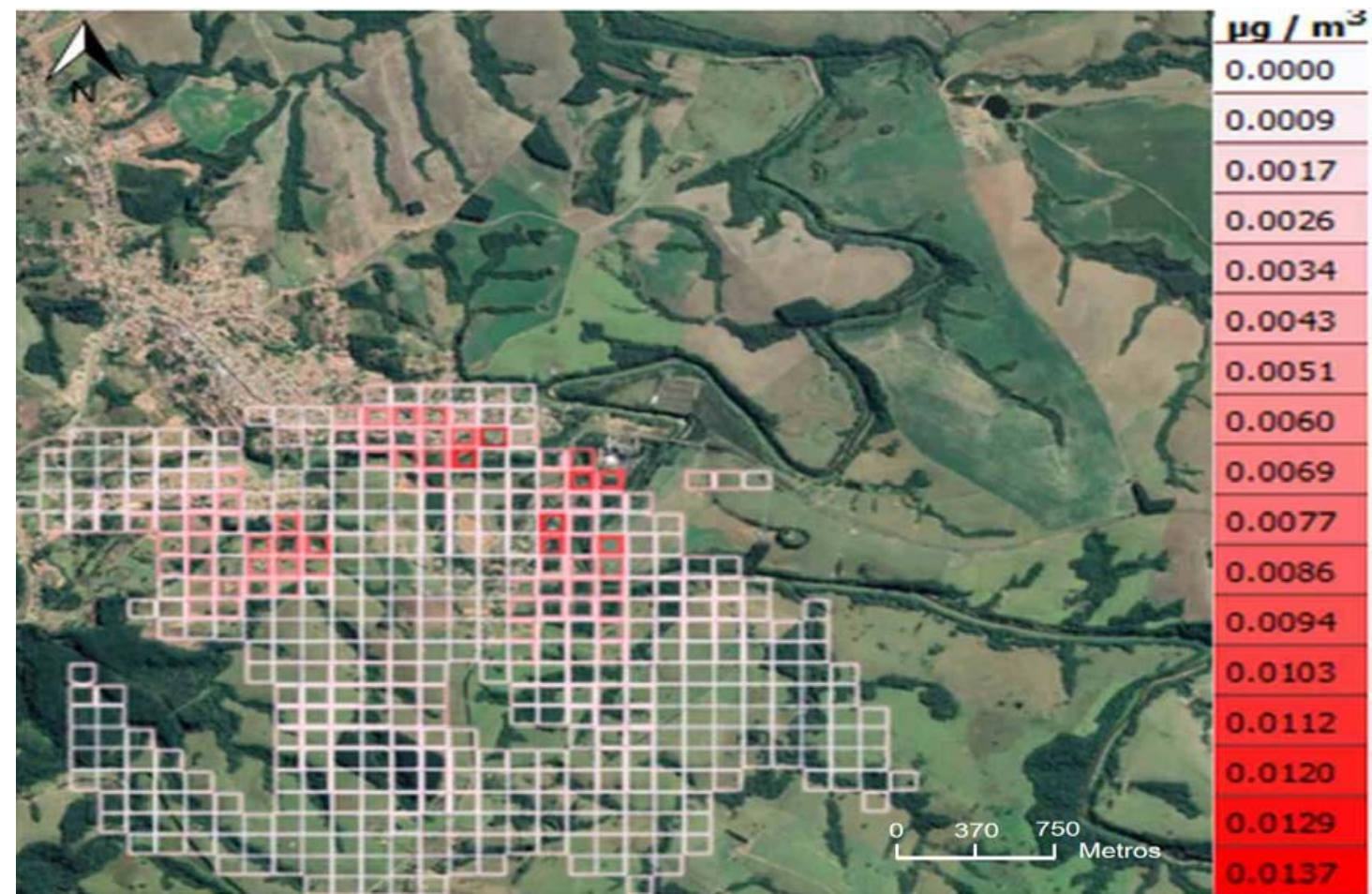

Figura 12. Dispersão de MP em junho de 2017 no SIMPACTS. Fonte: Google Earth. 


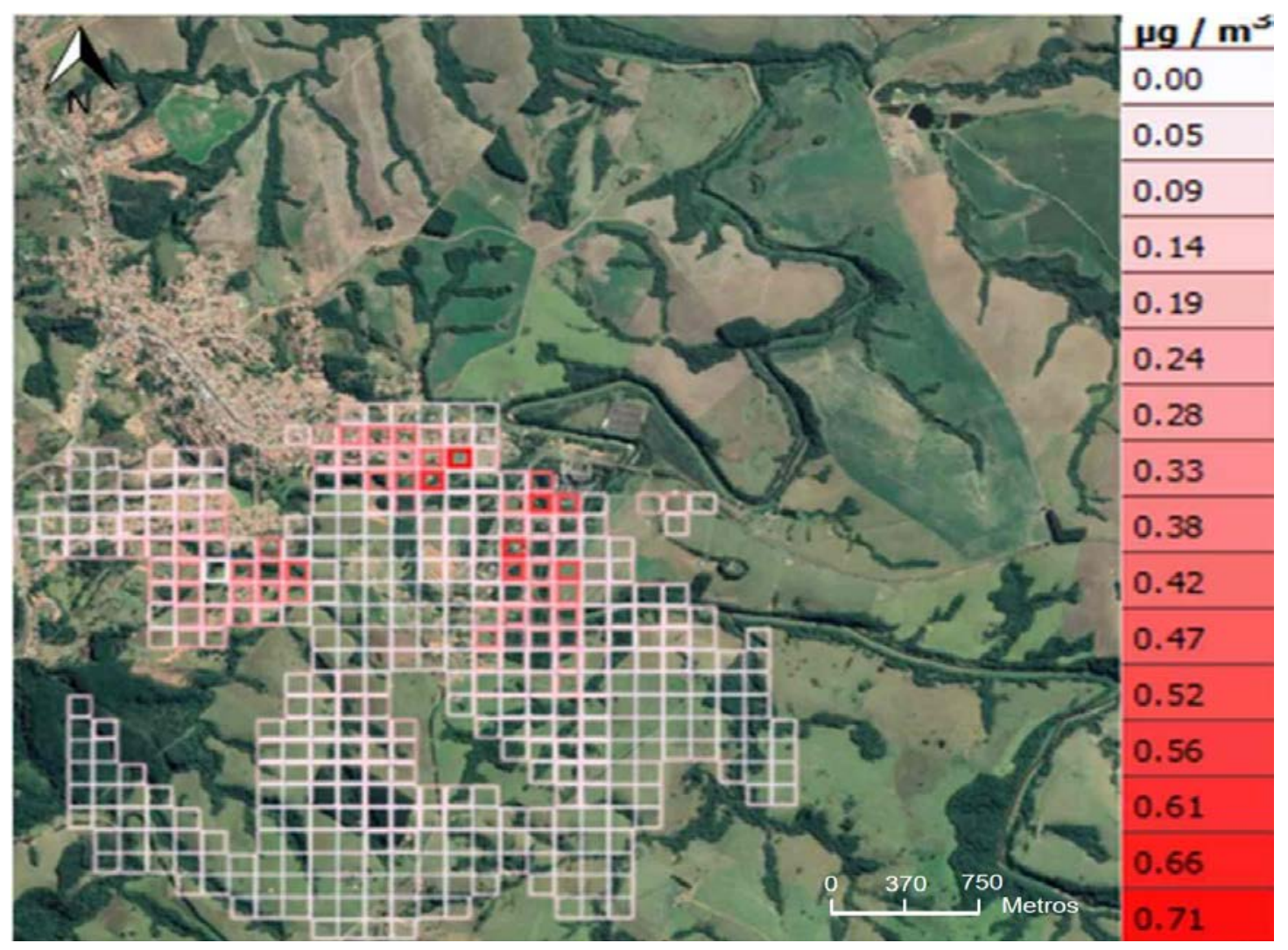

Figura 13. Dispersão de $\mathrm{SO}_{2}$ em junho de 2017 no SIMPACTS. Fonte: Google Earth.

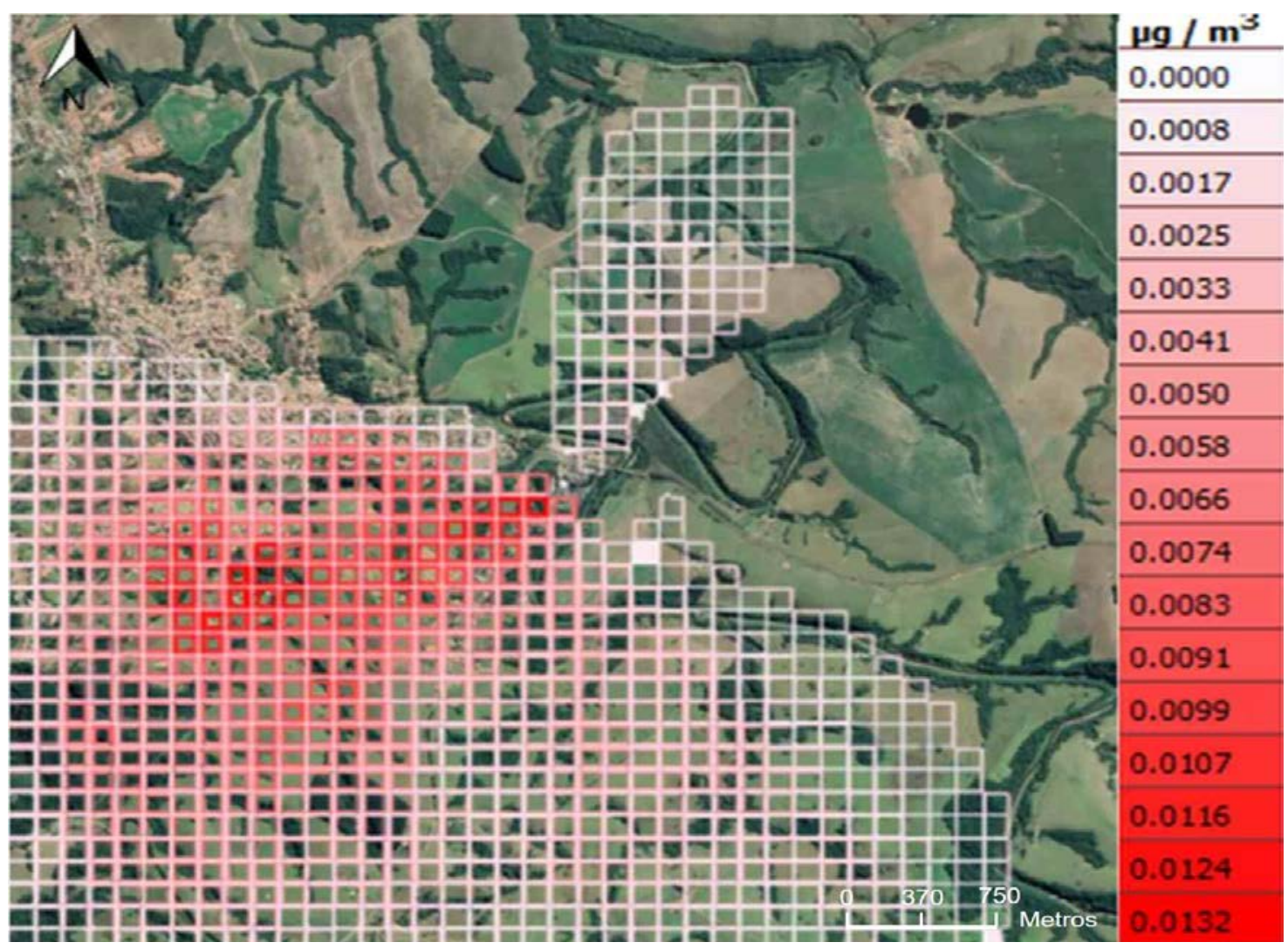

Figura 14. Dispersão de $\mathrm{SO}_{4}$ em junho de 2017 no SIMPACTS. Fonte: Adaptado de Google Earth. 
A diferença entre os anos de maior e menor emissão é perceptível através das dispersões dos gases. Em 2017 os poluentes atingem um número maior de pessoas e com concentrações maiores. A Tabela 6 mostra o quanto a concentração dos gases é maior de 2017 em relação ao ano de 2008.

Tabela 6. Diferença de concentração.

\begin{tabular}{|l|c|c|c|}
\hline Emissões & $\mathbf{2 0 0 8}$ & $\mathbf{2 0 1 7}$ & Diferença \\
\hline $\mathrm{SO}_{4}$ & $0,000169 \mu \mathrm{g} / \mathrm{m}^{3}$ & $0,0132 \mu \mathrm{g} / \mathrm{m}^{3}$ & 78,1 vezes maior \\
\hline $\mathrm{SO}_{2}$ & $0,0161 \mu \mathrm{g} / \mathrm{m}^{3}$ & $0,71 \mu \mathrm{g} / \mathrm{m}^{3}$ & 44 vezes maior \\
\hline $\mathrm{MP}$ & $0,0048 \mu \mathrm{g} / \mathrm{m}^{3}$ & $0,0137 \mu \mathrm{g} / \mathrm{m}^{3}$ & 7 vezes maior \\
\hline $\mathrm{NO}_{\mathrm{x}}$ & $0,00319 \mu \mathrm{g} / \mathrm{m}^{3}$ & $0,0104 \mu \mathrm{g} / \mathrm{m}^{3}$ & 3,2 vezes maior \\
\hline
\end{tabular}

As Tabelas 7 e 8 mostram os impactos convertidos em termos monetários obtidos no SIMPACTS em 2008 e 2017 por poluente atmosférico, levando em consideração o tipo de impacto, casos por ano e custo. Como esperado, o ano com menor emissão apresenta um custo três vezes menor para material particulado, 10,8 vezes menor para os nitratos e 11 vezes menor para os sulfatos. Totalizando, um impacto 6,1 vezes menor em $2008 \mathrm{em}$ relação a 2017.

Tabela 7. Custo por impacto e poluente $2008 \mathrm{em} 25 \mathrm{~km}^{2}$ calculado pelo SIMPACTS.

\begin{tabular}{|c|c|c|c|c|c|c|}
\hline $2008 / 5$ km x 5 km & \multicolumn{2}{|c|}{$\mathrm{MP}_{10}$} & \multicolumn{2}{|c|}{ Sulfatos } & \multicolumn{2}{|c|}{ Nitratos } \\
\hline Impacto & $\begin{array}{c}\text { Casos } \\
\text { por ano }\end{array}$ & $\begin{array}{c}\text { Custo } \\
\text { US\$/ano }\end{array}$ & $\begin{array}{l}\text { Casos por } \\
\text { ano }\end{array}$ & $\begin{array}{c}\text { Custo } \\
\text { US\$/ano }\end{array}$ & $\begin{array}{l}\text { Casos por } \\
\text { ano }\end{array}$ & $\begin{array}{c}\text { Custo } \\
\text { US\$/ano }\end{array}$ \\
\hline $\begin{array}{l}\text { Mortalidade crônica - } \\
\text { População inteira }\end{array}$ & 0,042 & 701,24 & 0,022 & 361,96 & 0,005 & 86.89 \\
\hline $\begin{array}{l}\text { Mortalidade infantil - } \\
\text { Menores de } 12 \text { meses }\end{array}$ & 0,00019 & 6,31 & 0,00000991 & 3,28 & 0,00000237 & 0,78 \\
\hline $\begin{array}{l}\text { Mortalidade aguda - } \\
\text { População inteira }\end{array}$ & 0,306 & 7,57 & 0,000159 & 3,93 & 0,0000379 & 0,94 \\
\hline $\begin{array}{l}\text { Uso de broncodilatador - } \\
\text { asma adultos, maiores de } \\
20 \text { anos }\end{array}$ & 0,334 & 0,12 & 0,173 & 0,06 & 0,041 & 0,01 \\
\hline $\begin{array}{l}\text { Uso de broncodilatador - } \\
\text { asma crianças, } 5-14 \text { anos }\end{array}$ & 0,039 & 0,01 & 0,076 & 0,03 & 0,005 & 0,0017 \\
\hline $\begin{array}{l}\text { Dificuldade respiratória - } \\
\text { adultos com dificuldade } \\
\text { respiratória crônica }\end{array}$ & 3,264 & 41,14 & 1,694 & 21,36 & 0,398 & 5,01 \\
\hline $\begin{array}{l}\text { Dificuldade respiratória - } \\
\text { Crianças de 5-14 anos }\end{array}$ & 2,183 & 27,52 & 1,133 & 14,29 & 0,27 & 3,41 \\
\hline $\begin{array}{l}\text { Restrição de atividades } \\
\text { diárias - Adultos que } \\
\text { trabalham, 15-64 anos }\end{array}$ & 2,508 & 107,5 & 1,302 & 55,8 & 0,3 & 12,86 \\
\hline $\begin{array}{l}\text { Restrição de atividades } \\
\text { diárias - Adultos que não } \\
\text { trabalham, 15-64 anos }\end{array}$ & 0,284 & 4,3 & 0,147 & 2,23 & 0,034 & 0,51 \\
\hline $\begin{array}{l}\text { Internação cardíaca - } \\
\text { População inteira }\end{array}$ & 0,000446 & 0,3 & 0,000231 & 0,15 & 0,0000552 & 0,04 \\
\hline $\begin{array}{l}\text { internação por problemas } \\
\text { respiratórios - População } \\
\text { inteira }\end{array}$ & 0,000724 & 0,48 & 0,000376 & 0,25 & $0,00009,29$ & 0,37 \\
\hline $\begin{array}{l}\text { Bronquite crônica } \\
\text { Adultos, maiores de } 27 \\
\text { anos }\end{array}$ & 0,002 & 127,58 & 0,001 & 66,22 & 0,000239 & 15,81 \\
\hline
\end{tabular}




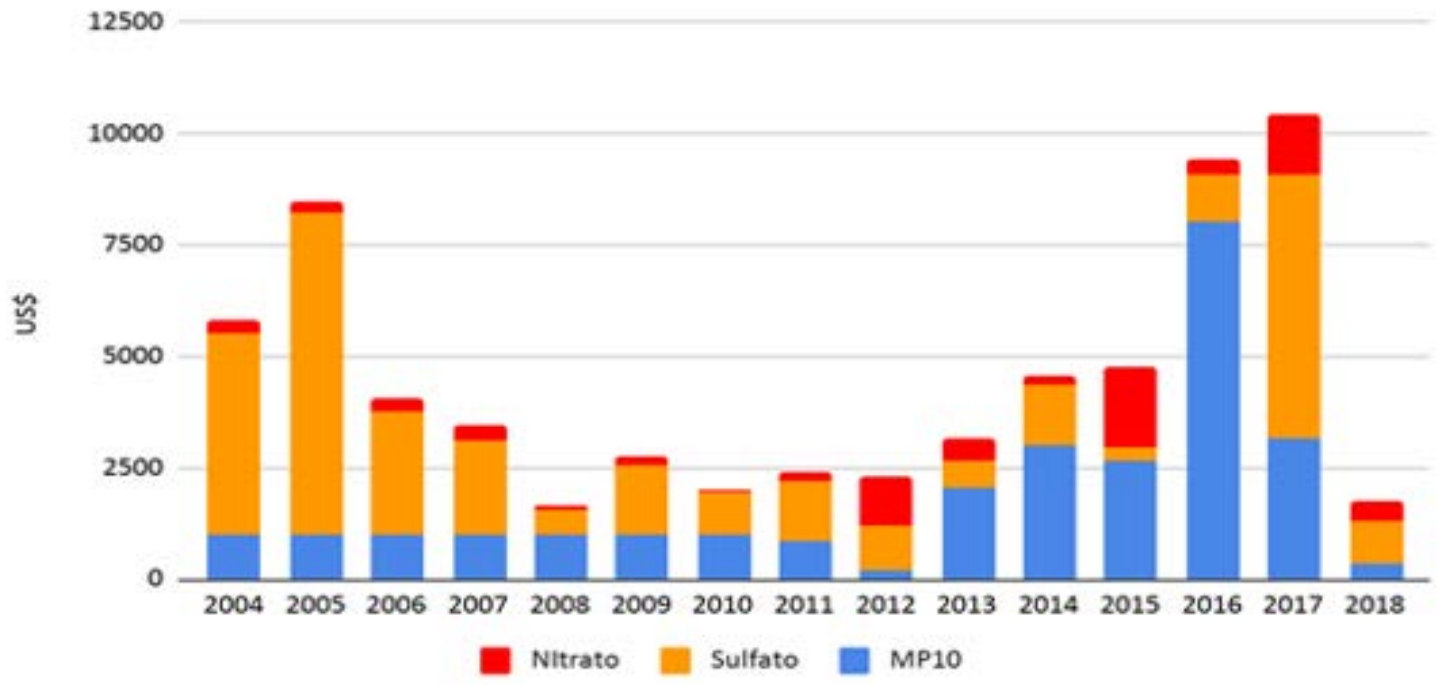

Figura 15. Impactos socioambientais convertidos em termos monetários: área $25 \mathrm{~km}^{2}$.

Tabela 8. Custo por impacto e poluente $2017 \mathrm{em} 25 \mathrm{~km}^{2}$ calculado pelo SIMPACTS.

\begin{tabular}{|c|c|c|c|c|c|c|}
\hline \multirow{2}{*}{$\begin{array}{l}2017 / 5 \text { km x } 5 \text { km } \\
\text { Impacto }\end{array}$} & \multicolumn{2}{|c|}{ MP10 $_{10}$} & \multicolumn{2}{|c|}{ Sulfatos } & \multicolumn{2}{|c|}{ Nitratos } \\
\hline & $\begin{array}{l}\text { Casos por } \\
\text { ano }\end{array}$ & $\begin{array}{c}\text { Custo } \\
\text { US\$/ano }\end{array}$ & $\begin{array}{l}\text { Casos por } \\
\text { ano }\end{array}$ & $\begin{array}{l}\text { Custo } \\
\text { US\$/ano }\end{array}$ & $\begin{array}{l}\text { Casos por } \\
\text { ano }\end{array}$ & $\begin{array}{l}\text { Custo } \\
\text { US\$/ano }\end{array}$ \\
\hline $\begin{array}{l}\text { Mortalidade cronica - } \\
\text { População inteira }\end{array}$ & 0,131 & $2.163,45$ & 0,246 & $4.060,07$ & 0,056 & 930,95 \\
\hline $\begin{array}{l}\text { Mortalidade infantil - } \\
\text { Menores de } 12 \text { meses }\end{array}$ & 0,0000589 & 19,47 & 0,000111 & 36,54 & 0,0000254 & 8,38 \\
\hline $\begin{array}{l}\text { Mortalidade aguda - } \\
\text { População inteira }\end{array}$ & 0,000943 & 23,36 & 0,002 & 43,85 & 0,000406 & 10,05 \\
\hline $\begin{array}{l}\text { Uso de broncodilatador - } \\
\text { asma adultos, maiores de } \\
20 \text { anos }\end{array}$ & 1,031 & 0,37 & 1,935 & 0,7 & 0,444 & 0,16 \\
\hline $\begin{array}{l}\text { Uso de broncodilatador - } \\
\text { asma crianças, 5-14 anos }\end{array}$ & 0,12 & 0,04 & 0,852 & 0,31 & 0,05 & 0,02 \\
\hline $\begin{array}{l}\text { Dificuldade respiratoria - } \\
\text { adultos com dificuldade } \\
\text { respiratoria crônica }\end{array}$ & 10,069 & 126,97 & 18,896 & 238,28 & 4,26 & 53,72 \\
\hline $\begin{array}{l}\text { Dificuldade respiratoria - } \\
\text { Crianças de 5-14 anos }\end{array}$ & 6,734 & 84,92 & 12,638 & 159,36 & 2,898 & 36,54 \\
\hline $\begin{array}{l}\text { Restrição de atividades } \\
\text { diárias - Adultos que } \\
\text { trabalham, 15-64 anos }\end{array}$ & 7,729 & 331,67 & 14,523 & 622,44 & 3,215 & 137,8 \\
\hline $\begin{array}{l}\text { Restrição de atividades } \\
\text { diárias - Adultos que nao } \\
\text { trabalham, 15-64 anos }\end{array}$ & 0,877 & 13,25 & 1,645 & 24,89 & 0,364 & 5,51 \\
\hline $\begin{array}{l}\text { Internação cardiaca - } \\
\text { Populção inteira }\end{array}$ & 0,001 & 0,92 & 0,003 & 1,72 & 0,000592 & 0,39 \\
\hline $\begin{array}{l}\text { internação por problemas } \\
\text { respiratorios - População } \\
\text { inteira }\end{array}$ & 0,002 & 1,49 & 0,004 & 2,79 & 0,000596 & 3,98 \\
\hline $\begin{array}{l}\text { Bronquite crônica } \\
\text { Adultos, maiores de } 27 \\
\text { anos }\end{array}$ & 0,006 & 393,62 & 0,011 & 738,7 & 0,003 & 169,38 \\
\hline
\end{tabular}


A Figura 15 apresenta a diferença entre os custos de cada ano por poluente. Representa, portanto, os impactos na saúde e os danos à agricultura, ou seja, os impactos socioambientais convertidos em dólares, causados pelo funcionamento da UTE. Além disso, o gráfico mostra a relevância de cada poluente no custo total. Para obter esta relação considera-se a quantidade emitida e o perigo da substância. Por exemplo, uma menor quantidade de material particulado é mais danosa a saúde que a mesma de sulfato, portanto, é possível observar em 2016 uma contribuição maior por parte do $\mathrm{MP}_{10} \mathrm{em}$ relação aos outros poluentes, apesar da emissão ter sido menor em relação ao sulfato e igual à de nitrato.

\section{Região de $2.500 \mathrm{~km}^{2}$ para o ano 2008}

Para a área de $2.500 \mathrm{~km}^{2}$, três municípios são incluídos pela área em estudo, com mais de 10.000 habitantes, dessa forma, os valores do dano à saúde aumentam. As Figuras 16-18 apresentam a dispersão de $\mathrm{NOx}, \mathrm{MP}, \mathrm{SO}_{2}$ para o ano com menor emissão de poluentes (2008), na área de $2500 \mathrm{~km}^{2}$. Estes mostram uma dispersão em dois quadrantes ao redor da usina, um deles na posição sul e o outro do lado oeste. Por outro lado, na Figura 19 é possível ver que a dispersão $\mathrm{SO}_{4}$ é espalhada em uma região maior ao redor da usina.

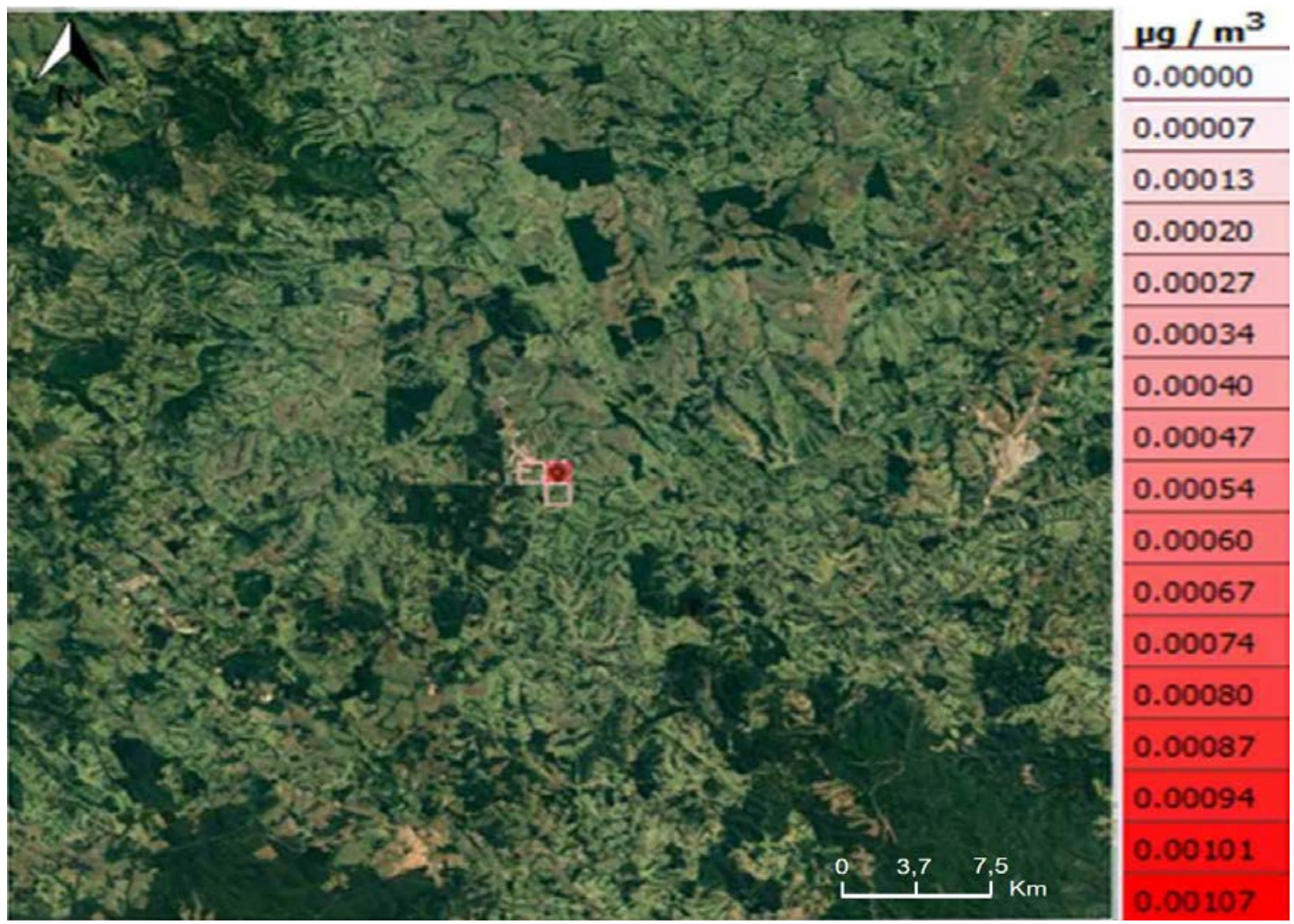

Figura 16. Dispersão de $\mathrm{NO}_{\mathrm{x}}$ em abril de 2008 no SIMPACTS. Fonte: Adaptado de Google Earth 


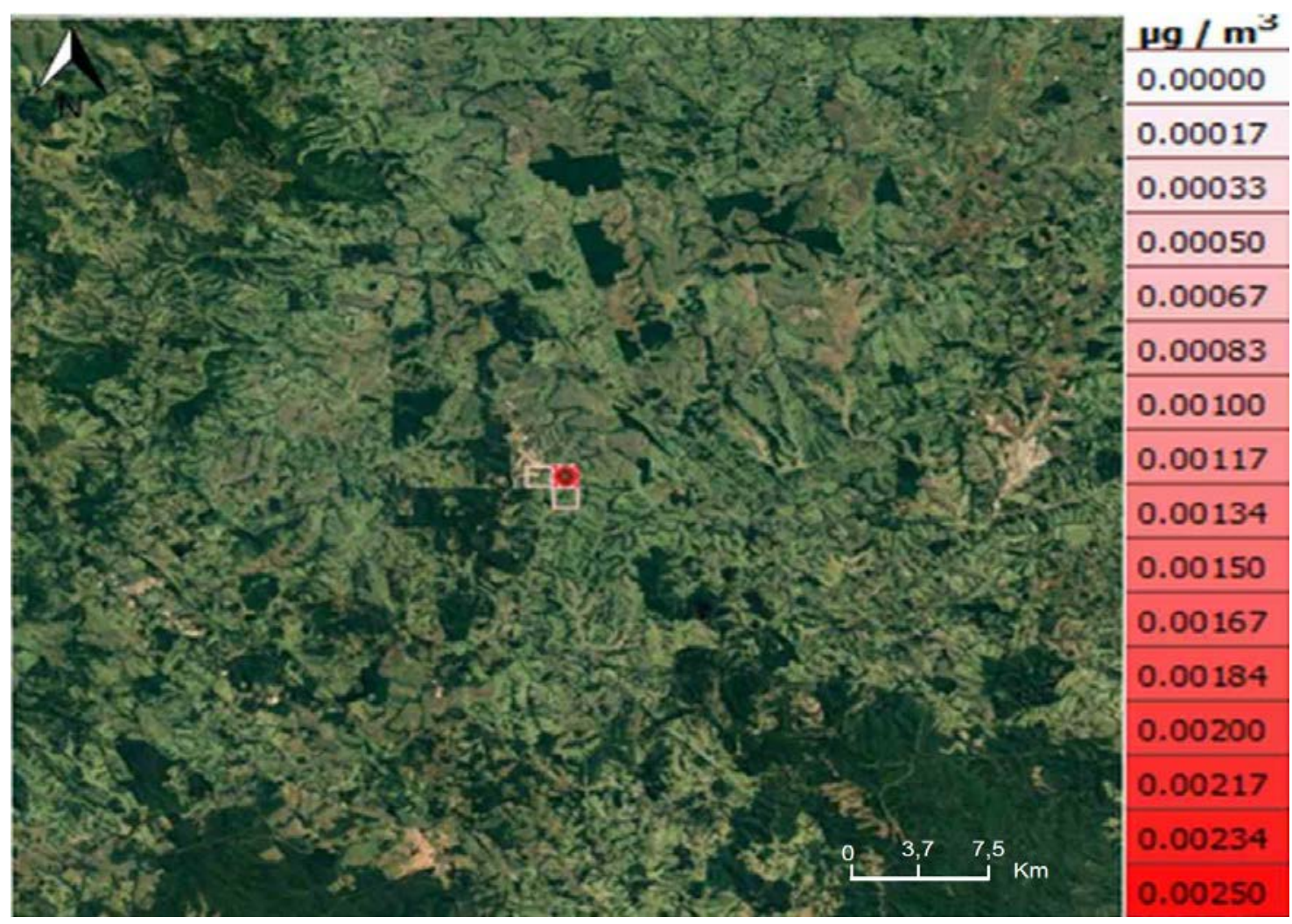

Figura 17. Dispersão de MP em abril de 2008 no SIMPACTS. Fonte: Adaptado de Google Earth.

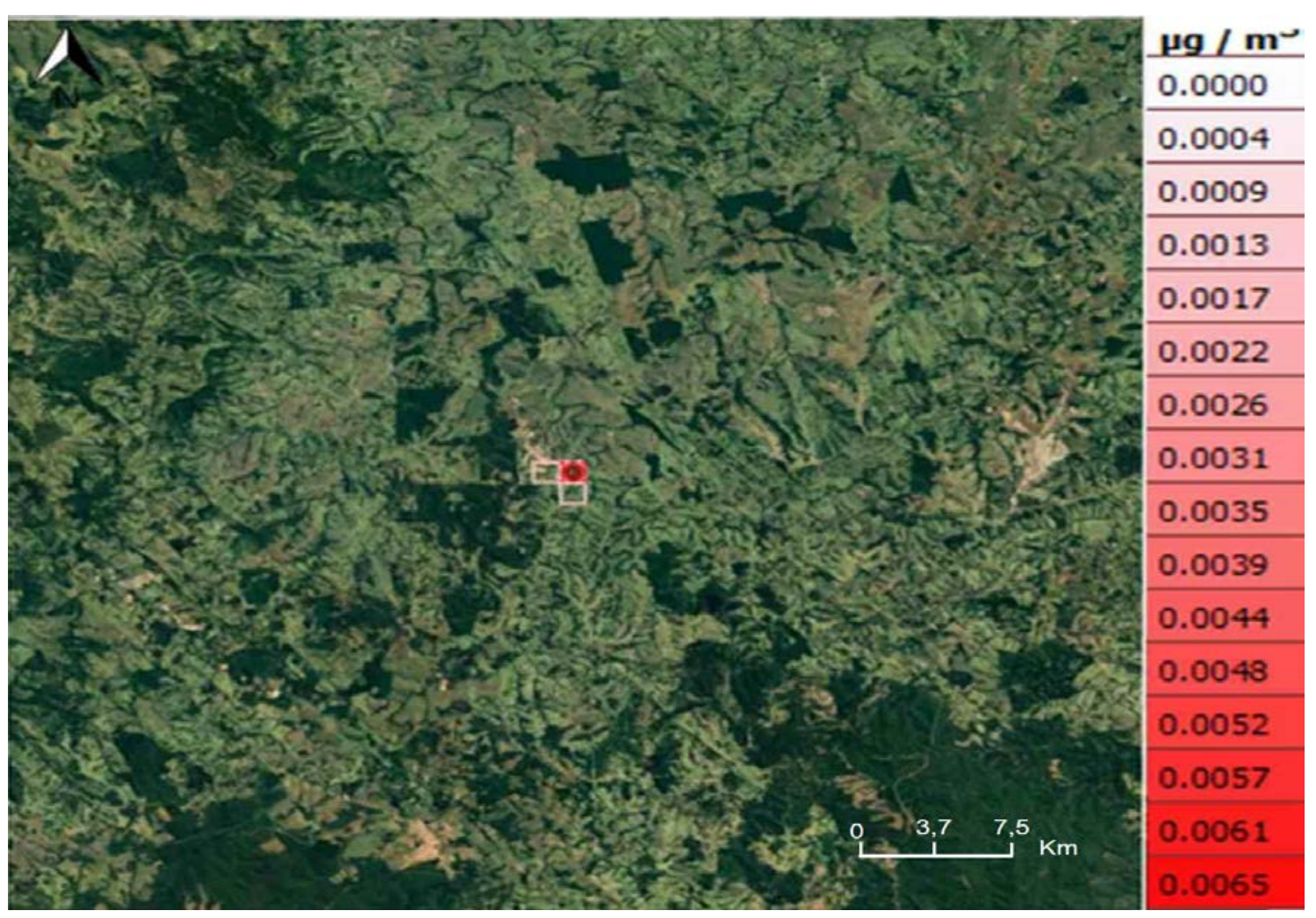

Figura 18. Dispersão de $\mathrm{SO}_{2}$ em abril de 2008 no SIMPACTS. Fonte: Adaptado de Google Earth 


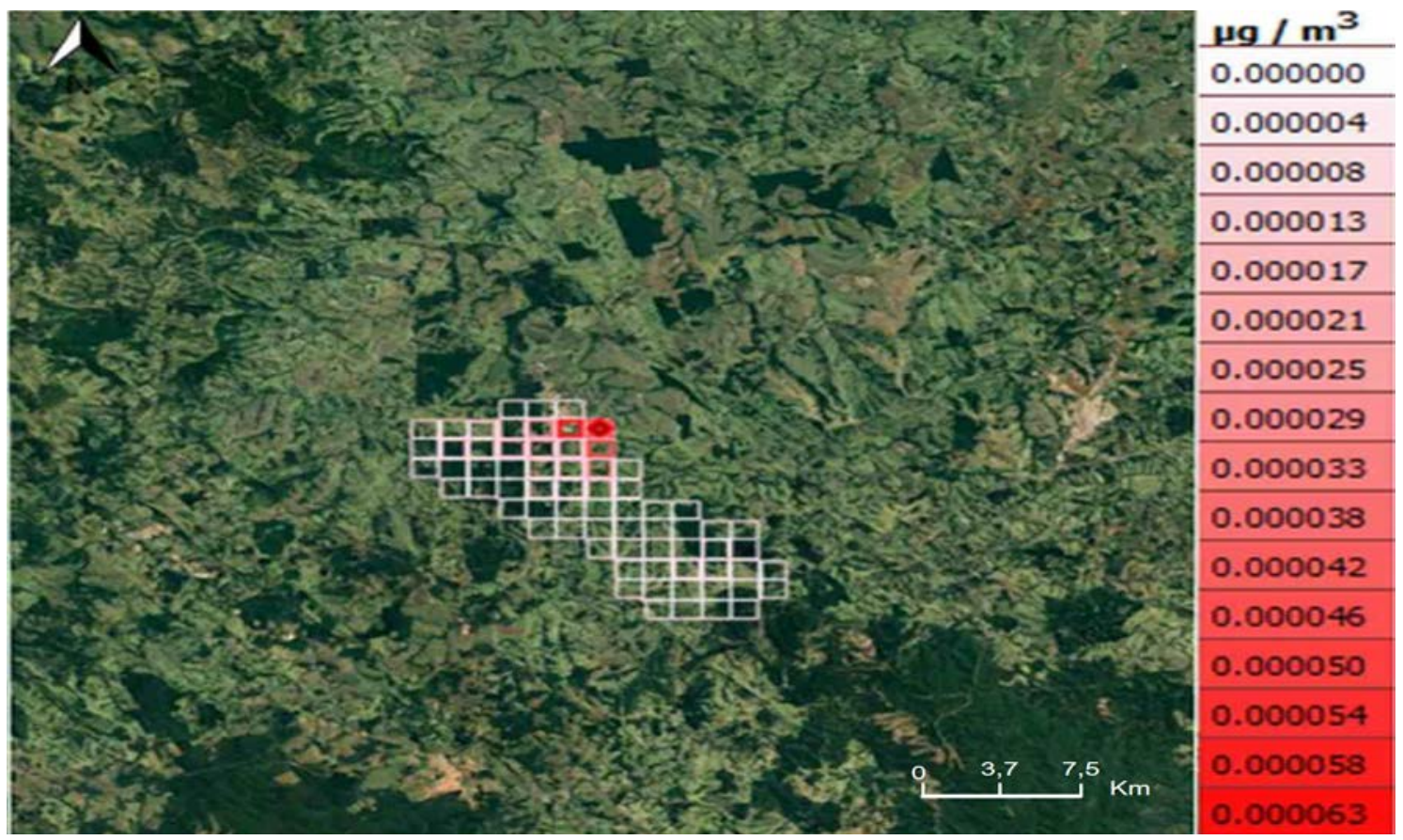

Figura 19. Dispersão de $\mathrm{SO}_{4}$ em abril de 2008 no SIMPACTS. Fonte: Adaptado de Google Earth.

\section{Região de 2.500 km² $^{2}$ para o ano 2017}

0 ano de 2017 é o ano com maior emissão, sendo possível observar maior intensidade e dispersão dos gases anteriormente avaliados. As Figuras 20-22 apresentam tendências de dispersão para oeste, sul e sudoeste e concentradas nas imediações de Figueira. Por outro lado, as emissões de $\mathrm{SO}_{4}$ apresentam uma dispersão com maior alcance em direção à região sudoeste e nordeste (Figura 23).

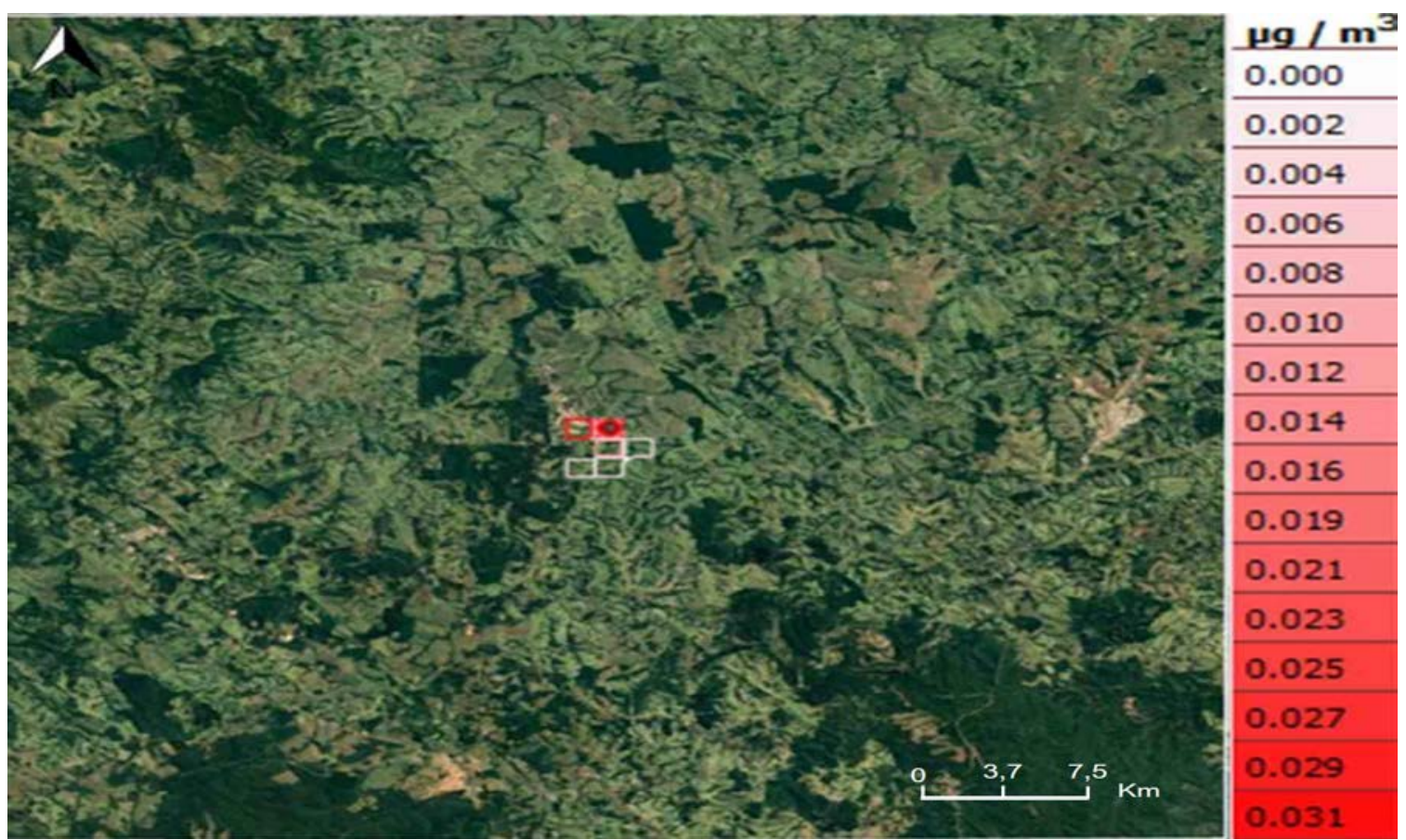

Figura 20. Dispersão de $\mathrm{NO}_{\mathrm{x}}$ em junho de 2017 no SIMPACTS. Fonte: Adaptado de Google Earth. 


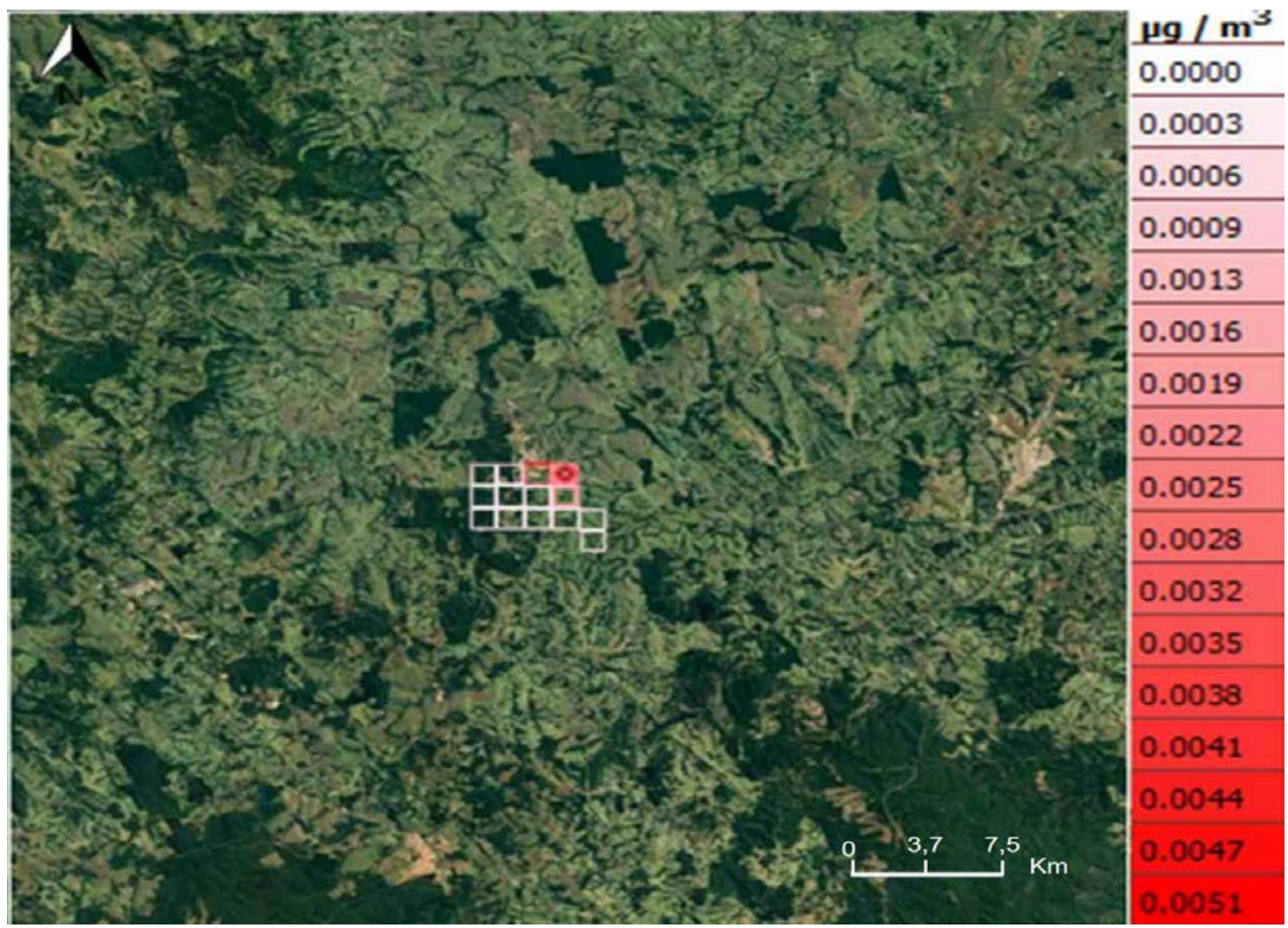

Figura 21. Dispersão de MP em junho de 2017 no SIMPACTS. Fonte: Adaptado de Google Earth

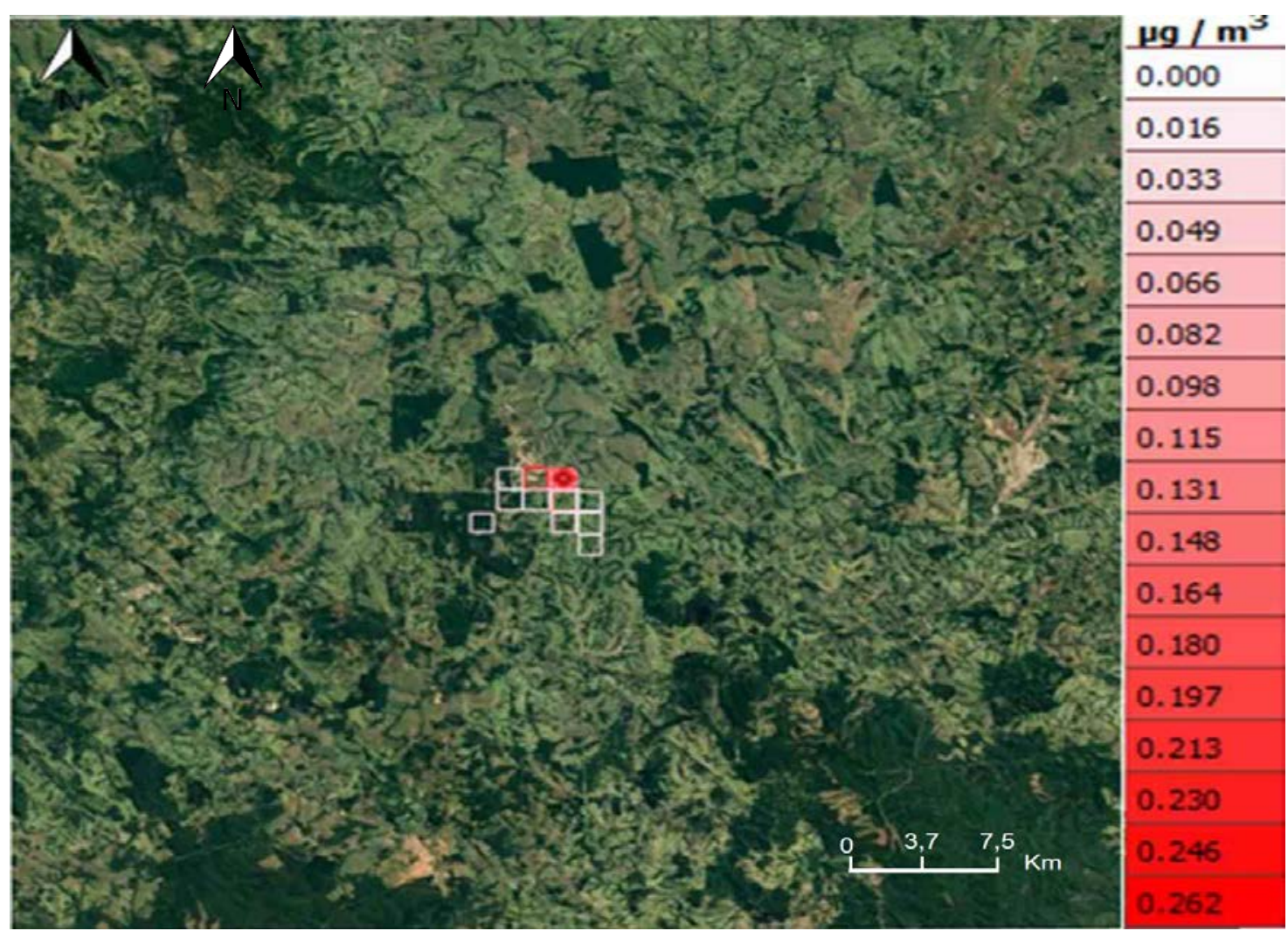

Figura 22. Dispersão de $\mathrm{SO}_{2}$ em junho de 2017 no SIMPACTS. Fonte: Adaptado de Google Earth 


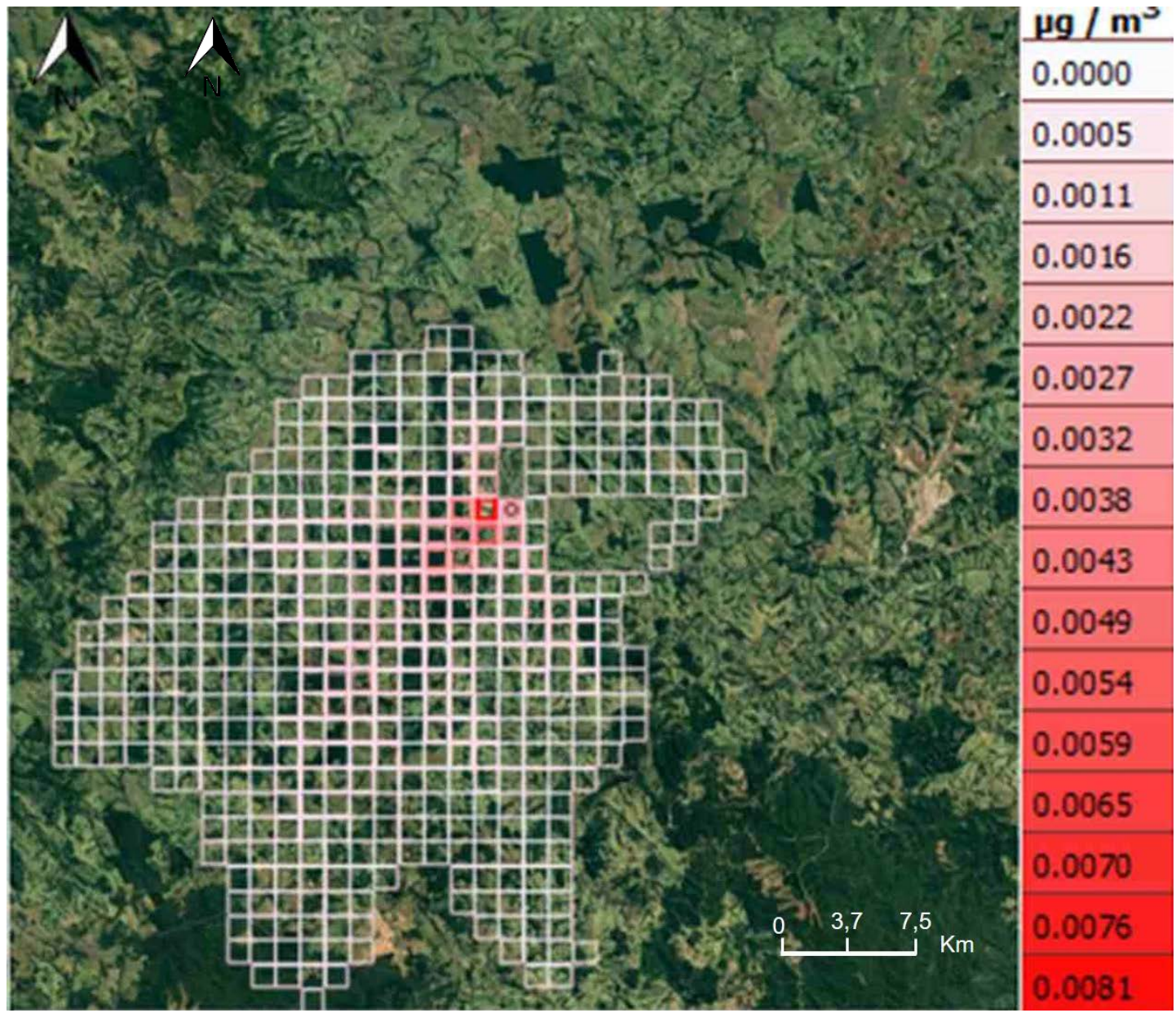

Figura 23. Dispersão de $\mathrm{SO}_{4}$ em junho de 2017 no SIMPACTS. Fonte: Google Earth.

Para $2.500 \mathrm{~km}^{2}$ também é possível observar a grande diferença na área de dispersão. Enquanto no ano com menor emissão (2008), a concentração dos gases tende a se conter apenas em Figueira, município sede da UTE, no ano com maior emissão (2017) os gases apresentam uma maior abrangência chegando até outros municípios. A diferença de concentração é grande entre os anos. A Tabela 9 mostra quantas vezes essa concentração é maior em 2017 em relação a 2008.

Tabela 9. Diferença de concentrações.

\begin{tabular}{l|c|c|c}
\hline Emissões & $\mathbf{2 0 0 8}$ & $\mathbf{2 0 1 7}$ & Diferença \\
\hline $\mathrm{SO}_{4}$ & $0,000063 \mu \mathrm{g} / \mathrm{m}^{3}$ & $0,0081 \mu \mathrm{g} / \mathrm{m}^{3}$ & 128,5 vezes maior \\
\hline $\mathrm{SO}_{2}$ & $0,0065 \mu \mathrm{g} / \mathrm{m}^{3}$ & $0,262 \mu \mathrm{g} / \mathrm{m}^{3}$ & 40,3 vezes maior \\
\hline $\mathrm{MP}$ & $0,00250 \mu \mathrm{g} / \mathrm{m}^{3}$ & $0,0051 \mu \mathrm{g} / \mathrm{m}^{3}$ & 2 vezes maior \\
\hline $\mathrm{NO}_{\mathrm{x}}$ & $0,00107 \mu \mathrm{g} / \mathrm{m}^{3}$ & $0,031 \mu \mathrm{g} / \mathrm{m}^{3}$ & 29 vezes maior \\
\hline
\end{tabular}


As Tabelas 10 e 11 mostram os custos obtidos no SIMPACTS, em dólares, referentes aos impactos de cada poluente. Para a área de $2500 \mathrm{~km}^{2}$, os valores são maiores se comparados à área de $25 \mathrm{~km}^{2}$. Além disso, em 2017 o custo foi maior que em 2008 aproximadamente 3,3,11,5 e 11 vezes para MP, sulfato e nitrato respectivamente, resultando em um valor total de aproximadamente 7,5 vezes maior.

Tabela 10. Custos por impacto e poluente $2008 \mathrm{em} 2500 \mathrm{~km}^{2}$ calculado pelo SIMPACTS.

\begin{tabular}{|c|c|c|c|c|c|c|}
\hline $2008 / 50 \mathrm{~km} \times 50$ & & & & tos & & tos \\
\hline Impacto & $\begin{array}{c}\text { Casos } \\
\text { por ano }\end{array}$ & $\begin{array}{c}\text { Custo } \\
\text { US\$/ano }\end{array}$ & $\begin{array}{c}\text { Casos } \\
\text { por ano }\end{array}$ & $\begin{array}{c}\text { Custo } \\
\text { US\$/ano }\end{array}$ & $\begin{array}{c}\text { Casos } \\
\text { por ano }\end{array}$ & $\begin{array}{c}\text { Custo } \\
\text { US\$/ano }\end{array}$ \\
\hline $\begin{array}{l}\text { Mortalidade crônica - } \\
\text { População inteira }\end{array}$ & 4.154 & 68622,48 & 3,73 & 62446,01 & 0,708 & 11705,09 \\
\hline $\begin{array}{l}\text { Mortalidade infantil - } \\
\text { Menores de } 12 \text { meses }\end{array}$ & 0,002 & 617,6 & 0,002 & 562,01 & $3,12 \mathrm{E}-04$ & 105,34 \\
\hline $\begin{array}{l}\text { Mortalidade aguda - } \\
\text { População inteira }\end{array}$ & 0,03 & 741,11 & 0,027 & 674,41 & 0,005 & 126,41 \\
\hline $\begin{array}{l}\text { Uso } \\
\text { broncodilatador } \\
\text { asma adultos, maiores } \\
\text { de } 20 \text { anos } \\
\end{array}$ & 32,71 & 11,72 & 29,789 & 10,72 & 5,579 & 2,01 \\
\hline $\begin{array}{lr}\text { Uso } & \text { de } \\
\text { broncodilatador } & - \\
\text { asma crianças, } & 5-14 \\
\text { anos } & \end{array}$ & 3,804 & 1,37 & 0,634 & 0,23 & 0,634 & 0,23 \\
\hline $\begin{array}{l}\text { Dificuldade } \\
\text { respiratória - adultos } \\
\text { com dificuldade } \\
\text { respiratória crônica }\end{array}$ & 319,373 & 4027,29 & 53,568 & 675,5 & 53,568 & 675,5 \\
\hline $\begin{array}{l}\text { Dificuldade } \\
\text { respiratória - Crianças } \\
\text { de 5-14 anos }\end{array}$ & 2013,601 & 2693,5 & 36,434 & 459,44 & 36,434 & 459,44 \\
\hline $\begin{array}{lr}\text { Restrição } & \text { de } \\
\text { atividades } & \text { diárias } \\
\text { Adultos } & \text { que } \\
\text { trabalham, } & 15-64 \text { anos } \\
\end{array}$ & 245,458 & 10520,33 & 40,425 & 1732,6 & 40,425 & 1732,6 \\
\hline $\begin{array}{lr}\text { Restrição } & \text { de } \\
\text { atividades diárias - } \\
\text { Adultos que não } \\
\text { trabalham, } & 15-64 \text { anos } \\
\end{array}$ & 27,807 & 420,72 & 4,58 & 69,29 & 4,58 & 69,29 \\
\hline $\begin{array}{l}\text { Internação cardíaca - } \\
\text { População inteira }\end{array}$ & 0,044 & 29,03 & 0,007 & 4,95 & 0,007 & 4,95 \\
\hline $\begin{array}{lr}\text { internação } & \text { por } \\
\text { problemas } & \\
\text { respiratórios } & - \\
\text { População inteira } & \\
\end{array}$ & 0,071 & 47,14 & 0,013 & 50,05 & 0,013 & 50,05 \\
\hline $\begin{array}{l}\text { Bronquite crônica - } \\
\text { Adultos, maiores de } \\
27 \text { anos }\end{array}$ & 0,189 & 12485,31 & 0,032 & 2129,65 & 0,032 & 2129,65 \\
\hline
\end{tabular}


Tabela 11. Custo por impacto e poluente $2017 \mathrm{em} 2500 \mathrm{~km}^{2}$ calculado pelo SIMPACTS.

\begin{tabular}{|c|c|c|c|c|c|c|}
\hline \multirow{2}{*}{$\begin{array}{l}2017 / 50 \mathrm{~km} \times 50 \\
\text { km } \\
\text { Impacto }\end{array}$} & \multicolumn{2}{|c|}{$\mathbf{M P}_{10}$} & \multicolumn{2}{|c|}{ Sulfatos } & \multicolumn{2}{|c|}{ Nitratos } \\
\hline & $\begin{array}{c}\text { Casos } \\
\text { por ano }\end{array}$ & $\begin{array}{c}\text { Custo } \\
\text { US\$/ano }\end{array}$ & $\begin{array}{c}\text { Casos por } \\
\text { ano }\end{array}$ & $\begin{array}{c}\text { Custo } \\
\text { US\$/ano }\end{array}$ & $\begin{array}{l}\text { Casos } \\
\text { por ano }\end{array}$ & $\begin{array}{c}\text { Custo } \\
\text { US\$/ano }\end{array}$ \\
\hline $\begin{array}{l}\text { Mortalidade crônica - } \\
\text { População inteira }\end{array}$ & 14,043 & $232.004,86$ & 43,447 & $717.792,98$ & 7,723 & $12.7586,11$ \\
\hline $\begin{array}{l}\text { Mortalidade infantil - } \\
\text { Menores de } 12 \text { meses }\end{array}$ & 0,006 & $2.088,02$ & 0,02 & $6.460,07$ & 0,003 & $1.148,25$ \\
\hline $\begin{array}{l}\text { Mortalidade aguda - } \\
\text { População inteira }\end{array}$ & 0,101 & $2.505,62$ & 0,313 & $7.752,05$ & 0,056 & $1.377,91$ \\
\hline $\begin{array}{c}\text { Uso de } \\
\text { broncodilatador - } \\
\text { asma adultos, maiores } \\
\text { de } 20 \text { anos } \\
\end{array}$ & 110,588 & 39,81 & 342,146 & 123,17 & 60,816 & 21,89 \\
\hline $\begin{array}{c}\text { Uso de } \\
\text { broncodilatador - } \\
\text { asma crianças, 5-14 } \\
\text { anos } \\
\end{array}$ & 12,86 & 4,63 & 150,544 & 54,2 & 6,915 & 2,49 \\
\hline $\begin{array}{c}\text { Dificuldade } \\
\text { respiratória - adultos } \\
\text { com dificuldade } \\
\text { respiratória crônica } \\
\end{array}$ & $1.079,764$ & 13.615 .82 & 3340,649 & $42.125,59$ & 583,896 & $7.362,93$ \\
\hline $\begin{array}{c}\text { Dificuldade } \\
\text { respiratória - Crianças } \\
\text { de 5-14 anos }\end{array}$ & 722,16 & $9.106,43$ & 2234,268 & $28.174,12$ & 397,136 & $5.007,89$ \\
\hline $\begin{array}{c}\text { Restrição de } \\
\text { atividades diárias - } \\
\text { Adultos que } \\
\text { trabalham, 15-64 } \\
\text { anos } \\
\end{array}$ & 829,866 & $35.568,04$ & 2567,497 & $110.042,92$ & 440,63 & $18.885,41$ \\
\hline $\begin{array}{c}\text { Restrição de } \\
\text { atividades diárias - } \\
\text { Adultos que não } \\
\text { trabalham, 15-64 } \\
\text { anos } \\
\end{array}$ & 94,013 & $1.422,41$ & 290,863 & $4.400,76$ & 49,918 & 755,25 \\
\hline $\begin{array}{l}\text { Internação cardíaca - } \\
\text { População inteira }\end{array}$ & 0,147 & 98,14 & 0,456 & 303,63 & 0,081 & 53,97 \\
\hline $\begin{array}{c}\text { internação por } \\
\text { problemas } \\
\text { respiratórios - } \\
\text { População inteira } \\
\end{array}$ & 0,239 & 159,36 & 0,741 & 493,04 & 0,136 & 545,53 \\
\hline $\begin{array}{c}\text { Bronquite crônica - } \\
\text { Adultos, maiores de } \\
27 \text { anos }\end{array}$ & 0,639 & $42.211,44$ & 1,976 & $130.596,72$ & 0,351 & $23.313,28$ \\
\hline
\end{tabular}

Na Figura 24 são apresentados os custos totais dos efeitos causados pela poluição atmosférica por ano e por poluente. A relevância de cada poluente nos efeitos socioambientais convertidos em unidades monetárias para a área de $2500 \mathrm{~km}^{2}$ é similar ao caso para a área de $25 \mathrm{~km}^{2}$. Em 2017, ano com maiores emissões, a relevância de sulfato para o resultado total é maior que de outros poluentes, ou seja, no referido ano a emissão de sulfato foi maior que o normal. 
2000000

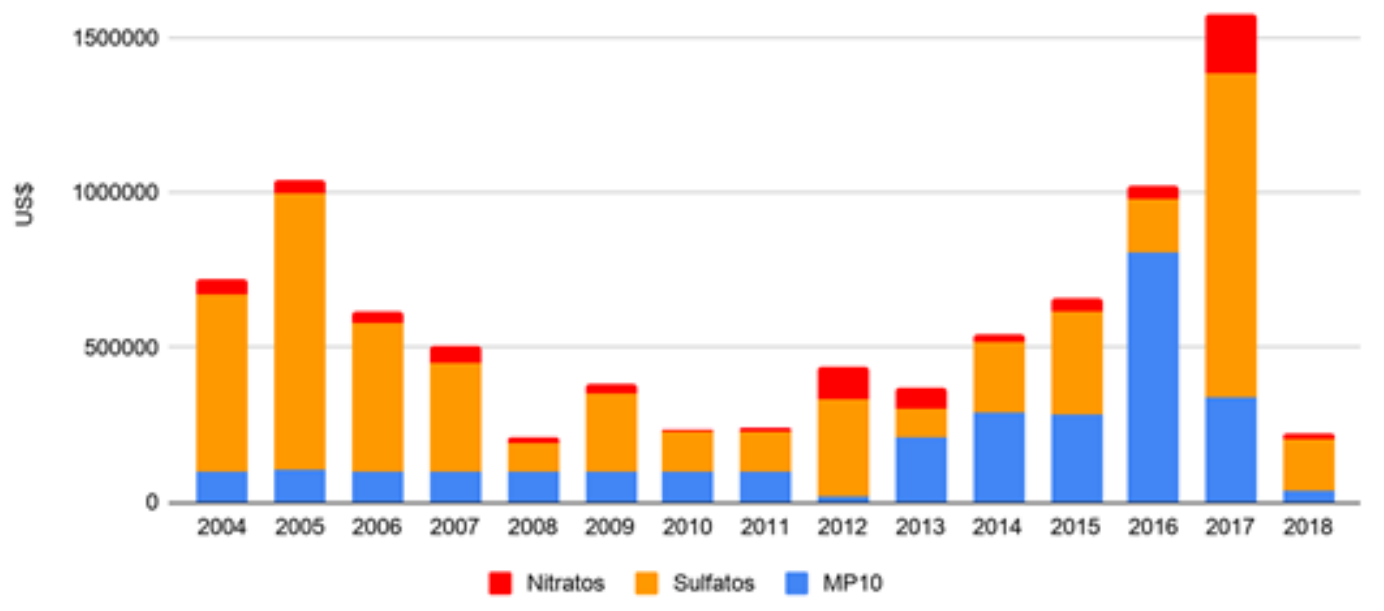

Figura 24. Impactos socioambientais convertidos em termos monetários: área $2500 \mathrm{~km}^{2}$.

Os custos obtidos no SIMPACTS referente aos efeitos na saúde e na agricultura em razão da geração de energia são mostrados na Tabela 12, possibilitando analisar os custos socioambientais por GWh dependendo da extensão da área em que os impactos são analisados. A diferença entre os custos está relacionada diretamente com a dimensão da área a ser estudada. Desta forma, a área com maior dimensão sempre terá um custo maior devido à sua abrangência. Para a área de $2.500 \mathrm{~km}^{2}$ o custo médio anual é de 4.475,50 US\$/GWh, enquanto para a área de $25 \mathrm{~km}^{2}$ tem-se uma média anual de 56,60 US\$/GWh.

Tabela 12. Custos socioambientais por geração elétrica para diferentes áreas.

\begin{tabular}{|c|c|c|}
\hline & $\begin{array}{l}\text { US\$/GWh } \\
\left(25 \mathrm{~km}^{2}\right)\end{array}$ & $\begin{array}{c}\text { US\$/GWh } \\
\left(2.500 \mathrm{~km}^{2}\right)\end{array}$ \\
\hline 2004 & 79,5 & $9.821,4$ \\
\hline 2005 & 104,8 & $12.872,9$ \\
\hline 2006 & 52,2 & $7.874,7$ \\
\hline 2007 & 43,5 & $6.283,3$ \\
\hline 2008 & 21,6 & $2.672,8$ \\
\hline 2009 & 31.5 & $4.379,9$ \\
\hline 2010 & 23,3 & $2.714,8$ \\
\hline 2011 & 28.2 & $4.169,8$ \\
\hline 2012 & 35,4 & $5.125,8$ \\
\hline 2013 & 36,6 & $4.311,1$ \\
\hline 2014 & 58,7 & $7.011,2$ \\
\hline 2015 & 53,9 & $7.495,2$ \\
\hline 2016 & 127,6 & $13.844,6$ \\
\hline 2017 & 116,5 & $17.675,3$ \\
\hline 2018 & 36,4 & $4.475,5$ \\
\hline
\end{tabular}




\section{Discussão}

No Brasil, a geração de energia elétrica por carvão mineral no Brasil ao redor de 3,2\%. Apesar de não ser uma das principais fontes de energia no país, a utilização do carvão mineral para geração de energia elétrica produz poluentes que podem afetar a população nas vizinhanças. Especialmente em épocas do ano, como em junho, onde os impactos ambientais aumentam devido à maior dispersão de poluentes geradas pelas correntes de ar na região em estudo.

A utilização de filtros como tecnologias para redução de poluentes pode contornar o desafio dos problemas à saúde nas cidades próximas e assim continuar mantendo a qualidade do ar. Alguns estudos para redução inclusive de gases de efeito estufa tem sido realizados para a redução das emissões de $\mathrm{CO}_{2}$ proveniente das usinas a carvão mineral na região (Hoffmann, 2013).

A participação da energia térmica a carvão mineral, é de grande importância nos estados de Paraná, Santa Catarina e Rio Grande do Sul. Inclusive a UTE em discussão encontra-se em fase de modernização, o que pode gerar uma redução maior ainda dos poluentes. No entanto, a queima de carvão mineral recebe subsídios estabelecido em lei, que representa ao redor de $\mathrm{R} \$ 710$ milhões de reais. Valor que pode ser considerado nas contas mensais de eletricidade e que compõe a conta de desenvolvimento energético (IDEC, 2020). Este investimento poderia ser utilizado para utilização de tecnologias de captura e sequestro de carbono, ou para investimento em tecnologias renováveis alternativas na região como eólica ou solar.

Dentro do PDE há uma indicação de retirada de 15,5GW de potência instalada de usinas, mas existe a possibilidade de aumento de eficiência ou substituição por usinas modernas em ciclo combinado ou até a substituição por gás natural o que levaria a uma redução significativa de emissões como $\mathrm{SO}_{\mathrm{x}}, \mathrm{NO}_{\mathrm{x}}$ e $\mathrm{MP}_{10}$ (EPE, 2021). No entanto, é importante considerar a segurança no fornecimento de energia elétrica fornecida pela usina que tem uma atividade quase constante.

Vale ressaltar que há uma incerteza para estimar alguns dados de entrada que foram empregados assim como alguns pressupostos em relação a algumas variáveis econômicas e técnicas, a qual podem afetar a avaliação monetária dos custos, dentre deles a desvalorização da moeda e crise econômica do Brasil nos últimos anos, assim pressupostos nas emissões em função da geração de energia elétrica.

\section{Conclusões}

A emissão de gases ou partículas causando poluição atmosférica é extremamente danosa à população e ao meio ambiente em qualquer quantidade. Contudo, normas para regular tais emissões visando a minimizar os impactos socioambientais são necessárias quando partem de atividades essenciais à população. 0 presente trabalho permitiu observar que a COPEL, a partir de 2007, começou a se preocupar com as emissões de poluentes atmosféricos através de programas e reformas internas, contudo nos últimos anos as emissões aumentaram de forma considerável, expondo os problemas da UTE. A disparidade entre os anos de maior e menor emissão ficam evidenciadas no estudo. Apesar de não haver grande diferença na geração de eletricidade nos anos 2008 e 2017, os impactos causados pelas emissões de poluentes foram entre 6,1 e 7,5 vezes maiores em 2017. Isso pode indicar que um controle mais rigoroso dessas emissões pode causar uma redução significativa dos seus impactos. As dispersões dos poluentes $\mathrm{NO}_{\mathrm{x}}, \mathrm{SO}_{2}$ e $\mathrm{MP}$ no entorno da UTE são bem semelhantes, enquanto o $\mathrm{SO}_{4}$ possui uma maior dispersão quando comparado aos demais. As emissões de MP apesar de serem menores em quantidades relativas aos demais poluentes, causam um impacto significativo no ambiente e na população do entorno da UTE localizada no município de Figueira elevando os custos dos danos à saúde e ao meio ambiente. Por fim, os custos socioambientais crescem quando a área de impacto levada em consideração na análise é maior.

Trabalhos futuros pretendem comparar os impactos causados entre usinas de mesmo tipo e entre diferentes tecnologias de geração de energia. 


\section{Agradecimentos}

Os autores agradecem às agências brasileiras de financiamento da pesquisa, Conselho Nacional de Desenvolvimento e Pesquisa (CNPq), Coordenação de Aperfeiçoamento de Pessoal de Nível Superior (CAPES), Comissão Nacional de Energia Nuclear (CNEN), Pró-Reitoria de Pesquisa (PRPq), da Universidade Federal de Minas Gerais pelos apoios concedidos.

\section{Referências}

Almeida, R. P. S.; Carvalho e Souza, T.; Souza, S. L. Q.; Martins, E. M.; Corrêa, S. M. Comparação da qualidade do ar em localidades industrial e urbana. Revista Internacional de Ciências, v. 9, n. 3, p. 47-62, 2019. https://doi.org/10.12957/ ric.2019.42897

Apro, P. H.; Pereira, V. S.; Rosal, C.; Souza, L. F. M.; Lamano-Ferreira, A. P. N.; Lamano Ferreira, M. Avaliação dos parâmetros de crescimento em plantas jovens de Phaseolus vulgaris L. (Feijão) expostas à poluição aérea da Cidade de São Paulo. Exacta, v. 10, n. 1, p. 92-100, 2012. https://doi.org/10.5585/exacta.v10n1.3217

Autodesk. AutoCAD. Versão para estudantes. 2020. Disponível em: <https://www.autodesk.com.br/education/free-software/autocad>. Acesso em: 10 maio 2020.

Boz Neto, J. Implantação do sistema de coleta de dados operacionais da Usina Termelétrica de Figueira - SCDCDE UTE FRA. Curitiba: Universidade Tecnológica Federal do Paraná, 2013. (Monografia de especialização).

Brasil. Ministério da Ciência, Tecnologia, Inovação e Comunicações. Estimativas anuais de emissões de gases de efeito estufa no Brasil. 4. ed. Brasília: Ministério da Ciência, Tecnologia, Inovação e Comunicações, 2017.

Brasil. Ministério da Saúde. Saúde Brasil 2018 - uma análise de situação de saúde e das doenças e agravos crônicos: desafios e perspectivas. Brasília: Ministério da Saúde, 2019. Disponível em: <http://bvsms.saude.gov.br/bvs/publicacoes/saude_brasil_2018_analise _situacao_saude_doencas_agravos_cronicos_desafios_perspectivas.pdf $>$. Acesso em: $24 \mathrm{abr}$. 2020.

Carbonífera Cambuí. Produtos - produção e exploração de carvão mineral. 2020. Disponível em: <http://www.carboniferadocambui.com.br/>. Acesso em: 24 mar. 2020.

COPEL - Companhia Paranaense de Energia. Relatório de Responsabilidade Socioambiental e Econômico-Financeiro. 2004. Disponível em: <https://www.copel.com/relatoriosanuais/2004/index_pt.htm>. Acesso em: 10 abr. 2020.

COPEL - Companhia Paranaense de Energia. Relatório de Responsabilidade Socioambiental e Econômico-Financeiro. 2005. Disponível em: <https://www.copel.com/relatoriosanuais/2005/index_pt.htm>. Acesso em: 10 abr. 2020.

COPEL - Companhia Paranaense de Energia. Relatório de Responsabilidade Socioambiental e Econômico-Financeiro. 2006. Disponível em: <https://www.copel.com/relatoriosanuais/2006/index_pt.htm>. Acesso em: 10 abr. 2020.

COPEL - Companhia Paranaense de Energia. Relatório de Responsabilidade Socioambiental e Econômico-Financeiro. 2007. Disponível em: <https://www.copel.com/relatoriosanuais/2007/index_pt.htm>. Acesso em: 10 abr. 2020. 
COPEL - Companhia Paranaense de Energia. Relatório de Responsabilidade Socioambiental e Econômico-Financeiro. 2008. Disponível em: <https://www.copel.com/relatoriosanuais/2008/index_pt.htm>. Acesso em: 10 abr. 2020. COPEL - Companhia Paranaense de Energia. Relatório de Responsabilidade Socioambiental e Econômico-Financeiro. 2009. Disponível em: <https://www.copel.com/relatoriosanuais/2009/index_pt.htm>. Acesso em: 10 abr. 2020.

COPEL - Companhia Paranaense de Energia. Relatório de Responsabilidade Socioambiental e Econômico-Financeiro. 2010. Disponível em: <https://www.copel.com/relatoriosanuais/2010/index_pt.htm>. Acesso em: 10 abr. 2020.

COPEL - Companhia Paranaense de Energia. Relatório de Responsabilidade Socioambiental e Econômico-Financeiro. 2011. Disponível em: <http://www.copel.com/hpcopel/root/sitearquivos2.nsf/arquivos/relatorio2011/\$FILE/ RelAnual11.pdf>. Acesso em: 10 abr. 2020.

COPEL - Companhia Paranaense de Energia. Relatório de Responsabilidade Socioambiental e Econômico-Financeiro. 2012. Disponível em: <https://ri.copel.com/ptb/relatorios-anuais-e-socioambientais/2012>. Acesso em: 10 abr. 2020.

COPEL - Companhia Paranaense de Energia. Relatório de Responsabilidade Socioambiental e Econômico-Financeiro. 2013. Disponível em: <http://www.copel.com/hpcopel/root/sitearquivos2.nsf/arquivos/relatorio_socioambie ntal_get_2013/\$FILE/Relatorio_Sustentabilidade_GeT_2013.pdf>. Acesso em: 10 abr. 2020.

COPEL - Companhia Paranaense de Energia. Relatório de Responsabilidade Socioambiental e Econômico-Financeiro. 2014. Disponível em: <http://www.copel.com/hpcopel/root/sitearquivos2.nsf/arquivos/relatorio_socioambie ntal_get_2014/\$FILE/Relatorio_Sustentabilidade_GeT_2014.pdf >. Acesso em: $10 \mathrm{abr}$. 2020 .

COPEL - Companhia Paranaense de Energia. Relatório de Responsabilidade Socioambiental e Econômico-Financeiro. 2015. Disponível em: <http://www.copel.com/hpcopel/root/sitearquivos2.nsf/arquivos/relatorio_socioambie ntal_get_2015/\$FILE/Relatorio_Sustentabilidade_GeT_2015.pdf >. Acesso em: 10 abr. 2020 .

COPEL - Companhia Paranaense de Energia. Relatório de Responsabilidade Socioambiental e Econômico-Financeiro. 2016. Disponível em: <http://www.copel.com/hpcopel/root/sitearquivos2.nsf/arquivos/relatorio2016/\$FILE/ RelAnual16.pdf>. Acesso em: 10 abr. 2020.

COPEL - Companhia Paranaense de Energia. Relatório de Responsabilidade Socioambiental e Econômico-Financeiro. 2017. Disponível em: <http://www.copel.com/hpcopel/root/sitearquivos2.nsf/arquivos/relatorio2017/\$FILE/ RelAnual17.pdf>. Acesso em: 10 abr. 2020.

COPEL - Companhia Paranaense de Energia. Relatório de Responsabilidade Socioambiental e Econômico-Financeiro. 2018. Disponível em: <https://www.copel.com/hpcopel/root/sitearquivos2.nsf/arquivos/relatorio_socioambie ntal_get_2018/\$FILE/COPEL GET 2018.pdf>. Acesso em: 10 abr. 2020. 
EPE - Empresa de Pesquisa Energética. Matriz energética e elétrica. 2020. Disponível em: <http://www.epe.gov.br/pt/abcdenergia/matriz-energetica-e-eletrica>. Acesso em: 22 abr. 2020.

EPE- Empresa de Pesquisa Energética. Plano Decenal de Expansão de Energia 2029. Disponível em: <https://www.epe.gov.br/pt/publicacoes-dados-abertos/publicacoes/ plano-decenal-de-expansao-de-energia-2029> Acesso em 25 mar. 2021.

Fard, R. F.; Naddafi, K.; Yunesian, M.; Nodehi, R. N.; Dehghani, M. H.; Hassanvand, M. S. The assessment of health impacts and external costs of natural gas-fired power plant of Qom. Environmental Science and Pollution Research, v. 23, p. 20922-20936, 2016. https://doi.org/10.1007/s11356-016-7258-0

Gomes, A. J. P.; Cruz, P. R.; Borges, L. P. Recursos minerais energéticos: carvão e urânio. In: Bizzi, L. A.; Schobbenhaus, C.; Vidotti, R. M.; Gonçalves, J. H. (Eds.). Geologia, tectônica e recursos minerais do Brasil: texto, mapas e SIG. Brasília: CPRM, 2003. p. 577-601.

Hainoun, A.; Almoustafa, A.; Seif Aldin, M. Estimating the health damage costs of Syrian electricity generation system using impact pathway approach. Energy, v. 35, p. 628-638, 2010. https://doi.org/10.1016/j.energy.2009.10.034

Hoffmann, B. S. O potencial termelétrico a carvão no Rio Grande do Sul diante restrições de disponibilidade de água e objetivos de redução de emissões de $\mathrm{CO}_{2}$, aplicando a queima em leito fluidizado. Rio de Janeiro: UFRJ/COPPE, 2013. (Tese de doutorado).

IDEC - Instituto Brasileiro de Defesa do Consumidor. Usinas termoelétricas e a crise no setor elétrico brasileiro pela COVID 19. 2020. Disponível em: <https://idec.org.br/ sites/default/files/relatorio_tecnico_portfolio_energia_final_web_2.pdf>. Acesso em: 28 maio 2020.

IAEA - International Atomic Energy Agency. Energy modelling tools. 2020. Disponível em: <https://www.iaea.org/topics/energy-planning/energy-modelling-tools>. Acesso em: 28 maio 2020.

IBGE - Instituto Brasileiro de Geografia e Estatística. 2010. Disponível em: $<$ https://cidades.ibge.gov.br/>. Acesso em: 28 maio 2020.

Jorli, M.; Van Passel, S.; Sadeghi, H.; Nasseri, A.; Agheli, L. Estimating human health impacts and costs due to Iranian fossil fuel power plant emissions through the impact pathway approach. Energies, v. 10, p. 2136, 2017. https://doi.org/10.3390/en10122136

Nwanya, S. C. Climate change and energy implications of gas flaring for Nigeria. International Journal of Low-Carbon Technologies, v. 6, n. 3, p. 193-199, 2011. https://doi.org/10.1093/ijlct/ctr007

ONS - Operador Nacional do Sistema Elétrico. Histórico de operações. 2020. Disponível em: <http://www.ons.org.br/paginas/resultados-da-operacao/historico-da-operacao>. Acesso em: 10 abr. 2020.

Parry, M.; Canziani, O.; Palutikof, J.; Van der Linden, P.; Hanson, C. (Eds.). Climate change 2007 - impacts, adaptation and vulnerability: Working group II contribution to the fourth assessment report of the IPCC. Cambridge: Cambridge University Press, 2007. v. 4. Disponível em: <https://www.ipcc.ch/site/assets/uploads/2018/03/ar4_wg2_full_ report.pdf>. Acesso em: 20 abr. 2020. 
Pedruzzi, R.; Baek, B. H.; Henderson, B. H.; Aravanis, N.; Pinto, J. A.; Araujo, I. B.; Nascimento, E. G. S.; Reis Junior, N. C.; Moreira, D. M.; Albuquerque, T. T. A. Performance evaluation of a photochemical model using different boundary conditions over the urban and industrialized metropolitan area of Vitória, Brazil. Environmental Science and Pollution Research, v. 26, p. 16125-16144, 2019. https://doi.org/10.1007/s11356-01904953-1

Rohde, G. M.; Machado, C. S. Quantificação das cinzas de carvão fóssil produzidas no Brasil. Porto Alegre: Cientec, 2016. (Boletim técnico, 36). Disponível em: <http://www.cientec.rs.gov.br/upload/20160708140547boletim_tecnico_36.pdf>. Acesso em: 24 mar. 2020.

Tolmasquim, M. T. Energia termelétrica: gás natural, biomassa, carvão, nuclear. Rio de Janeiro: EPE, 2016. 